\title{
Fine Particle Filtration Technology Using Fiber as Dust Collection Medium ${ }^{\dagger}$
}

\author{
Chikao Kanaoka \\ ${ }^{1}$ Kanazawa University, Japan
}

\begin{abstract}
Researches relating dust collector using fiber as particle collection body i.e., air filter, cartridge filter and nonwoven bag filter, were reviewed. Their filtration process was classified into 3 stages, i.e., Stage 1.inner filtration I, Stage 2.inner filtration II and Stage 3.surface filtration. Collection mechanisms of fresh circular fiber have been well understood and so-called classic filtration theory is applicable except single nano-particle, where discussion about the possibility of thermal rebound is necessary. In Stage 1, effects of shape of both fiber and particle, and filter structure, non-uniformity are the important issues. In Stages 2 and 3, filtration process becomes very complicated because of many affecting parameters. Main target in Stage 2 is to develop effective scheme to describe the phenomena and to find filter structure having a large holding capacity. Most important issue in Stage 3 is to develop the effective cleaning technique to minimize the dust emission based on rational but not empirical scheme.
\end{abstract}

Keywords: dust collection by fiber, collection mechanism, thermal rebound, dust holding capacity, dust cleaning

\section{Introduction}

Air pollution by particulate matter, especially PM 2.5 is still a big issue or it is getting even worse because of rapid industrialization of developing countries, especially Northeast Asia and generation of secondary particles in the atmosphere. Nano safety is also a big issue in the field of nano-particle production. Air quality of workplace environment is important from the point of view of workers' health control. All of these issues are closely related to the elimination of particulate matter from air. However, particle size and concentration ranges are too broad to handle by only one dust collector and thus various types of dust collectors have been used to solve these problems. Among them, "filters using fiber" such as air filter, bag filter and cartridge filters play very important role because of excellent collection performance and relatively low cost. They are common in using as a particle collection body, but are different at principal working principle, filter structure and the covering area and so on.

Particle collection by the use of filter is a kind of old technology and thus the number of studies has been done from various view points and subjects. Even so, they are still needed and area of demand is expanding. Hence it is

Received 4 September 2017; Accepted 14 November 2017 J-STAGE Advance published online 31 March 2018

1 Kakuma-machi, Kanazawa, Ishikawa, 920-1192, Japan

E-mail : kanaoka-4215@mail.bbexcite.jp inevitable to understand the filtration phenomena and their applications.

Hence in this paper, filtration phenomena and theoretical and experimental researches, and their practical applications will be reviewed.

\section{Classification of filter and collection behaviour}

Fig. 1 shows a rough sketch of covering area of those filters. As seen from the figure, the covering area of filters ranges broad in both particle size and concentration, i.e., particle size ranges from order of several ten micron meters to nano meters and particle concentration from more than several dozen $\mathrm{g} / \mathrm{m}^{3}$ to several particles $/ \mathrm{m}^{3}$ or less. In the figure, applicable area of each filter is shown by different colors and main usages or purposes of each filter are also written in individual area.

The area of air filters locates at lower concentration range. Covering particle size and concentration range of air filter depends on the filter performance, i.e., middle efficiency filter covers larger size and high particle concentration area, high efficiency filter locates at the middle, and high efficiency particulate air (HEPA) filter and Ultra low Penetration air (ULPA) filter, locate very fine size and low concentration area.

Most important feature of air filters is that they collect particles inside the medium. Once filter becomes dust 


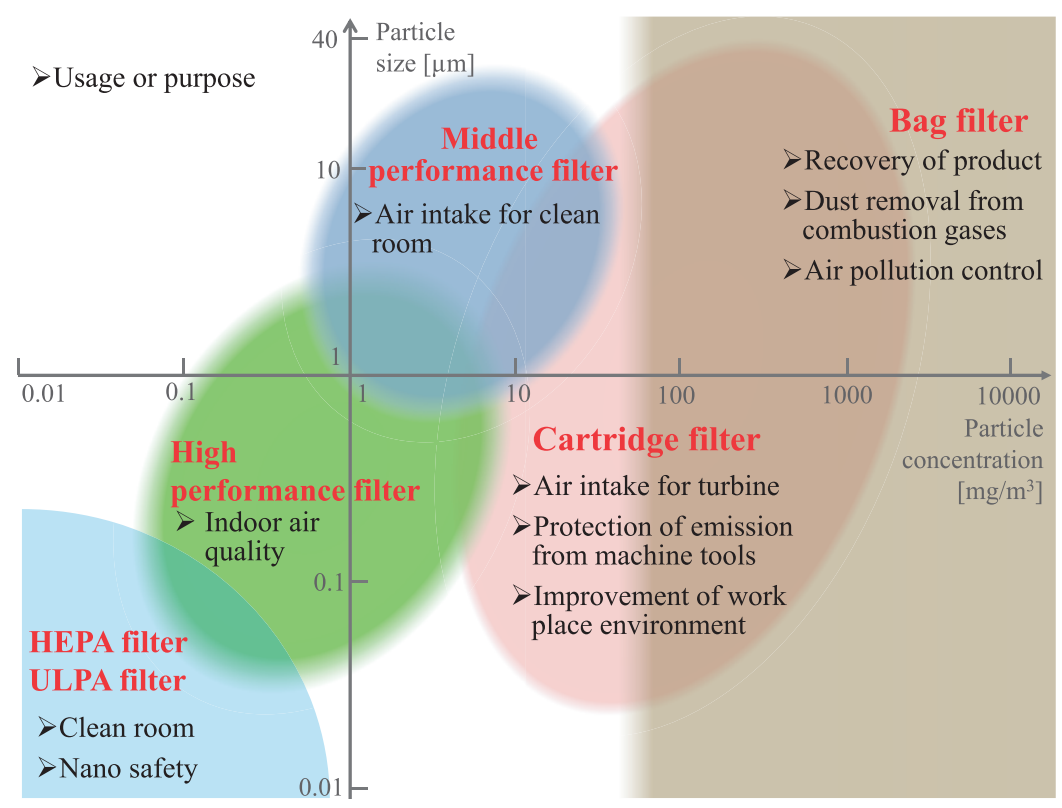

Fig. 1 Area map of filters against particle size and concentration.

loaded, especially for the case of solid particles, they stay and accumulate on the fiber. As a result, pressure drop across the filter rises with filtration time and particles accumulated inside the filter is too hard to remove them, i.e., regeneration of filter is extremely hard and thus air filter is usually discarded. Hence to increase the holding capacity of filter is an important issue. Collection of very fine particle like nano-size particle is another important issue for them.

Bag filter locates at the highest dust concentration range as high as ten $\mathrm{g} / \mathrm{m}^{3}$ or more, and cover whole particle size range. Cartridge filter is a kind of new type of filter and its coverage area overlaps almost but a little lower concentration compared with bag filter. Different from air filters, they are used at high particle concentration area, especially to recover powder products from industrial processes to suppress particulate emission of flue gas. Of course initial particle collection by a fresh filter takes place inside the filter, but it soon shifts to surface collection. Captured particles form a dust layer and it plays the actual collection medium, which collect particles almost perfectly regardless of particle size. Since dust layer becomes thicker with time and increases the flow resistance, it has to be removed occasionally to maintain continual operation. This also requires the filter medium to have sufficient mechanical strength against pressure drop.

Although two types of bag filter such as nonwoven and woven bag filters have been used for dust collection, nonwoven type bag filter is popularly used so that it increases practical importance now. Hence, discussion about woven type bag filter is eliminated in this article.

Table 1 compares the indices of 3 typical filters. They are different in many items like fiber size, thickness, packing density and etc. But they are still similar in using independent fibers to collect particles. Hence, they can be regarded as "air filters".

If a fresh air filter is operated for a long time, its collection behavior changes to 3 stages with time as,

Stage 1: Particles are collected by any fibers in the filter (inner filtration I). Rigorously, this stage is the period until first particle is collected but in practice, it is regarded as the period when pressure drop and/or collection efficiency of the filter stay almost the same.

Stage 2: Particles are collected by both fresh and dust loaded fibers in the filter (inner filtration). In this stage, gas flow pattern near the dust loaded fiber changes due to the change of apparent fiber shape and thus filter collection efficiency and pressure drop increase rapidly.

This stage can be defined as the period between the starting time of pressure drop and filter efficiency increase, to the time before clogging of the filter.

Stage 3; Particles are collected on the filter surface and forms porous dust cake, pore size of which is about same size with incoming particles (surface filtration). In this stage, particles arrived to the filter are collected by the dust cake almost perfectly regardless of particle size and pressure drop increases linearly.

Air filters used at Stages 1 and 2 are middle and high performance filters, and HEPA and ULPA filters. Main purpose of the usage of air filter, especially HEPA and ULPA filter, is to make clean air into much cleaner air. To achieve this, it uses fine fibers to enhance fine particle collection. Although it can use for a long time because of low inlet particle concentration, it cannot use no longer than the holding capacity of the filter, which is unknown but does not exceed its void. Hence to increase the hold- 
Table 1 Comparison of indices of filters.

\begin{tabular}{|c|c|c|c|}
\hline Item & HEPA filter & Cartridge filter & Nonwoven bag filter \\
\hline Fiber material & Glass, polymer & Polymer & Polymer \\
\hline Fiber size & Fine $(<2 \mu \mathrm{m})$ & Coarse $(10 \sim 20 \mu \mathrm{m})$ & Coarse $(10 \sim 20 \mu \mathrm{m})$ \\
\hline Packing density & Low $(<0.15)$ & $\operatorname{High}(>0.25)$ & $\operatorname{High}(>0.25)$ \\
\hline Fiber mass per area & Low $\left(<100 \mathrm{~g} / \mathrm{m}^{2}\right)$ & Middle $\left(100 \sim 300 \mathrm{~g} / \mathrm{m}^{2}\right)$ & High $\left(300 \sim 900 \mathrm{~g} / \mathrm{m}^{2}\right)$ \\
\hline Process & Paper making & Thermal-compression & Needle punching \\
\hline Re-generation & Non cleanable, discard & Cleanable, Re-use & Cleanable, Re-use \\
\hline
\end{tabular}

ing capacity is one of important subjects for air filter. Nano-size particle removal is another important issue for air filter, too.

Cartridge and bag filters are used at higher dust concentration. Important issue for them is how to reduce the amount of emission accompanying to cleaning process of dust cake from filter surface.

By the injection of cleaning air, most dust cake is removed to the dirty side of filter but small amount of dust is emitted from the clean side of the filter, by the back flow of cleaning air and dirty gas because almost no dust remains on and in the filter, i.e., emitted amount strongly depends on the collection performance of the filter itself. Furthermore some dust remains and forms firm deposit in the filter. Finally it effects on the life time of the filter.

\subsection{Particle collection at Stage 1}

This stage can be defined as the period when particle collection takes place on a clean fiber, i.e., no particle is collected on the fiber. Hence strictly speaking, this situation holds only at the point of the usage of the filter, but practically it is considered as the time duration no significant changes in filter efficiency and pressure drop are raised due to captured particles in the filter.

Capturing dynamics of particles is the basic of air filtration and thus it has been investigated from various view point. Hence many books and reviews have been published (Fuchs N.A., 1964; Davies C.N., 1966; Yeh H.C. and Liu B.Y.H., 1974a, b; Kirsch A.A. and Stechkina I.B., 1978; Brown R.C., 1993; Friedlander S.K., 1977, 2000; Hinds W.C., 1999).

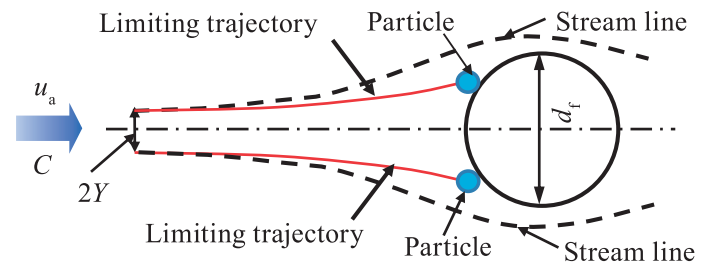

Fig. 2 Definition of single fiber collection efficiency.

\subsubsection{Filter efficiency $E$ and single fiber collection efficiency $\eta$}

When a fresh air filter is composed of same size circular fibers and they are arranged perpendicular to the mean gas flow and are packed uniformly, filter efficiency is expressed by Eqn. (1) (Davies C.N., 1952)

$$
E=1-\exp \left(-\frac{4}{\pi} \frac{\alpha}{1-\alpha} \frac{L}{d_{\mathrm{f}}} \eta\right)
$$

In Eqn. (1), parameters other than $\eta$ are related to filter itself. Hence, filter efficiency $E$ can be estimated only by knowing the value of $\eta$ for given filtration condition.

Single fiber collection efficiency $\eta$ is defined as the mass ratio between particles captured on the fiber and total income particles in the projection area of the fiber in a unit time. Hence when the limiting particle trajectory is uniquely determined by solving the motion equation of particle such as collection by inertia, interception and gravity and so on, $\eta$ is determined by Eqn. (2) by finding the inlet height of limiting trajectories, shown in Fig. 2.

$$
\eta=\left(C u_{\mathrm{a}} \cdot 2 Y\right) /\left(C u_{\mathrm{a}} d_{\mathrm{f}}\right)=Y /\left(d_{\mathrm{f}} / 2\right)
$$

$u_{\mathrm{a}}$ in Eqn. (2) is the approaching velocity of particle to the fiber and is $1 /(1-\alpha)$ times of filtration velocity $u$.

For the case of diffusion, deposition rate is calculated 
by kndwing the concentration profile of particle near the fiber surface by solving convective diffusion equation or Langevin equation.

From the previous studies, it is known that single fiber collection efficiency is a function of following dimensionless parameters.

$$
\begin{aligned}
& \text { Reynolds number: } R e=\frac{\rho_{\mathrm{g}} d_{\mathrm{f}} u}{\mu} \\
& \text { Stokes number: } S t k=\frac{C_{\mathrm{C}} \rho_{\mathrm{p}} d_{\mathrm{p}}{ }^{2} u}{9 \mu d_{\mathrm{f}}}
\end{aligned}
$$

Peclet number: $P e=\frac{d_{\mathrm{f}} u}{D_{\mathrm{BM}}}$

Gravitational parameter: $G=\frac{\rho_{\mathrm{p}} d_{\mathrm{p}}{ }^{2} g}{18 \mu u}$

Interception parameter: $R=\frac{d_{\mathrm{p}}}{d_{\mathrm{f}}}$

$$
\eta=\eta(R e, S t k, P e, G, R)
$$

Eqns. (3) to (7) express the degree of influence of flow field near the fiber, particle inertia, diffusion, gravity and interception, respectively.

\subsection{Single fiber collection efficiency by mechanical effect}

\subsubsection{Inertia and inertia-interception $\eta_{\mathrm{I}}, \eta_{\mathrm{IR}}$}

Collection efficiency is calculated from limiting trajectory for a given set of $S t k, R$ and $R e$. Early studies were performed for the impingement of mass particle to the fiber at potential and viscous flow fields (Landahl H.D. and Hermann R.G., 1949; Davies C.N. and Peetz C.V., 1956; Yoshioka, N. 1967a).

Davies C.N., (1952) also gave an approximate expression for $R e=0.2$ as,

$$
\eta_{\mathrm{IR}}=0.16\{R+(0.25+0.5 R) S t k-0.0263 R \cdot S t k\}
$$

However, flow field changes significantly by neighboring fibers, i.e., fiber packing density $\alpha$ (Kuwabara S., 1959; Happle, J., 1959). Fuchs N.A. and Stechikina I.B. (1963) first used Kuwabara flow model. Then flow calculation based on so-called "Kuwabara cell" became popular. Brown R.C. $(1984,1986)$ solved a flow through fibers in parallel by Fourie series analysis at low Re. Yoshioka N. (1969a), Emi H. et al. $(1973,1977)$ discussed the effect of $\alpha$ on $\eta_{\mathrm{IR}}$ in broad $R e$ region.

Fig. 3 compares calculated inertia-interception efficiencies $\eta_{\mathrm{IR}}$ for $R=0.1$ but different $\alpha$ such as 0 and 0.1 .

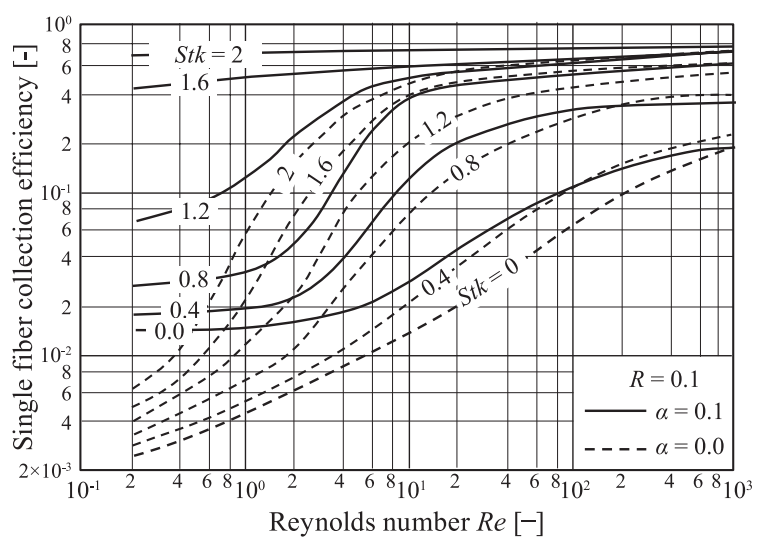

Fig. 3 Inertia-interception efficiency vs. Re. (Modified from Emi H. et al., 1977)

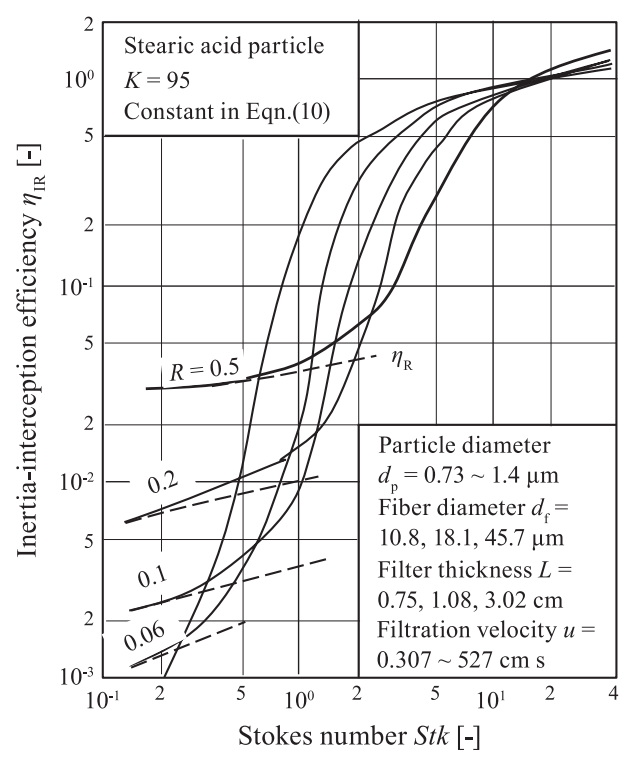

Fig. 4 Theoretical change of $\eta_{\mathrm{IR}}$ with Stk. (Modified from Yoshioka N. et al., 1969a).

Clearly seen from the figure, difference of $\eta_{\mathrm{IR}}$ at small $R e$ is large but decreases with $R e$.

Wong J.B. et al. (1956) measured collection efficiency of $0.4-1.3 \mu \mathrm{m}$ sulfuric acid particle by a glass mat and compared with their theory. Friedlander S.K. $(1957,1958)$ correlated $\eta$ with $S t k, R$ and $R e$. Effect of fiber diameter, packing density and etc. on $\eta_{\mathrm{IR}}$ was discussed by Iinoya $\mathrm{K}$. et al. (1965, 1970), Kimura N. and Iinoya K. (1965), Kimura N. (1969b), Makino K. and Iinoya K. (1969b), Lee K.W. and Liu B.Y.H. (1981). Yoshioka N. et al, (1967a, c, 1969a), Nguyen X. and Beeckmans J.M. (1975), Emi H. et al. $(1973,1977)$ calculated $\eta_{\mathrm{IR}}$ for various $S t k, R$ and $R e$, and compared their experimental efficiency in Fig. 4.

Clearly seen form the figure, increasing trend of $\eta_{\mathrm{IR}}$ looks little unusual at small and large $S t k$, i.e., $\eta_{\mathrm{IR}}$ is large for large $R$ but at intermediate $S t k, \eta_{\mathrm{IR}}$ for small $R$ is larger than that for larger $S t k$. This unusual change is explained 
bo contsidering that $S t k$ is the product of $R e$ and $R^{2}$ as shown in the following equation, i.e., changing $S t k$ in the experiment also changes the flow, i.e., Re simultaneously. Significant contribution of each parameter appears at different and thus this is the reason of the inversion in $\eta_{\mathrm{IR}}$ in intermediate Stk.

$$
S t k=\frac{C_{\mathrm{c}}}{9} \frac{\rho_{\mathrm{p}}}{\rho_{\mathrm{g}}} \frac{d_{\mathrm{f}} u \rho_{\mathrm{g}}}{\mu}\left(\frac{d_{\mathrm{p}}}{d_{\mathrm{g}}}\right)^{2}=K \cdot R e \cdot R^{2}
$$

\subsubsection{Interception $\eta_{\mathrm{R}}$ and gravity $\eta_{\mathrm{GR}}$}

When particles do not have inertia, they move along with gas stream and are collected on a fiber by interception. Collection efficiency in this situation was solved analytically by Langmuir I. (1942) for viscous flow (Lamb H., 1932) and potential flow, given by Eqns. (11) and (13), respectively.

Viscous flow $R e=0$

$$
\eta_{\mathrm{R}}=\frac{1}{2 h}\left[2(1+R) \ln (1+R)+\frac{1}{1+R}-(1+R)\right]
$$

Here, $h$ is hydrodynamic factor for an isolated fiber and is expressive as,

$$
h_{\mathrm{L}}=2-\ln \operatorname{Re} \text { (Lamb's factor) }
$$

Potential flow $\operatorname{Re}=\infty$

$$
\eta_{\mathrm{R}}=(1+R)-\frac{1}{1+R}
$$

Stechkina I.B. and Fuchs N.A. (1966) obtained Eqn. (11) by using Kuwabara's hydrodynamic factor $h_{\mathrm{K}}$ in a group of parallel fibers (Kuwabara S., 1959).

$$
h_{\mathrm{K}}=-\frac{1}{2} \ln \alpha+\alpha-\alpha^{2} / 4-3 / 4
$$

Yoshioka N. and Emi, H. (1967b) also derived an approximate expression of Eqn. (11) as,

$$
\eta_{\mathrm{R}} \cong \frac{1.25}{2 h} R^{1.82}
$$

Lee K.W. and Liu B.Y.H. (1981) also derived a similar expression as

$$
\eta_{\mathrm{R}}=\frac{1}{2 h} R^{2}
$$

Kimura and Iinoya (1965) obtained Eqn. (17) from velocity distribution in the boundary layer on a cylinder.

$$
\eta_{\mathrm{R}} \cong \frac{1}{3} R e^{1 / 2} R^{2}
$$

Kirsh A.A. et al. (1975), Brown R.C. and Wake D. (1991) and Hubbard J.A. et al. (2012) studied intercep- tion efficiency at different conditions. For the case of interception-gravity, efficiency also depends on flow direction, Yoshioka et al. (1972) obtained analytical expressions by taking account of orientation of filter and flow as shown below,

$$
\text { Viscous flow } R e=0
$$

Horizontal flow (filter is placed vertical)

$$
\begin{aligned}
\eta_{\mathrm{GR}}= & \frac{1+R}{\sqrt{1+G^{2} \sqrt{1+\left(R^{2} / h G\right)^{2}}}} \\
& \times\left\{\frac{R^{2}\left[1 /(1+R)^{2}-1+\ln (1+R)^{2}\right]}{2 h^{2} G}\right\}+G
\end{aligned}
$$

Vertical down flow

$$
\eta_{\mathrm{GR}}=\frac{1+R}{1+G}\left\{\frac{1}{2 h}\left[\frac{1}{(1+R)^{2}}-1+\ln (1+R)^{2}\right]+G\right\}
$$

Potential flow $R e=\infty$

Horizontal flow

$$
\eta_{\mathrm{GR}}=\frac{\sqrt{(1+R)^{4} G^{2}+\left[(1+R)^{2}-1\right]^{2}}}{(1+R) \sqrt{1+G^{2}}}
$$

Vertical down flow

$$
\eta_{\mathrm{GR}}=\frac{1}{1+G}\left[G(1+R)-\frac{1}{1+R}+(1+R)\right]
$$

When $G=0$, Eqns. (18) and (19) become Eqn. (11) and Eqns. (20) and (21) become Eqn. (13). Thomas J.W. et al. (1971) also discussed the effect of gravity.

\subsubsection{Diffusion, diffusion-interception $\eta_{\mathrm{D}}, \eta_{\mathrm{DR}}$}

Particle collection by diffusion and diffusion-interception effect is important for very fine particles, especially nanosize particles.

For mass point particles, most of analytical expressions obtained for viscous flow are proportion to $P e^{-2 / 3}$ as (Langmuir I., 1942; Friedlander S.K., 1957; Natanson G.L., 1957b; Stechkina I.B. and Fuchs N.A., 1966; Kirsch A.A. and Fuchs N.A., 1968; Lee K.W. and Liu B.Y.H., 1981).

$$
\eta_{\mathrm{D}}=A h^{1 / 3} P e^{-2 / 3}
$$

(Langmuir, Friedlander, Natanson, Lee and Liu)

$$
\eta_{\mathrm{D}}=2.9 h_{\mathrm{K}}^{1 / 3} P e^{-2 / 3}+0.62 P e^{-1}
$$

(Stechkina and Fuchs)

Natanson derived the following expression for potential 


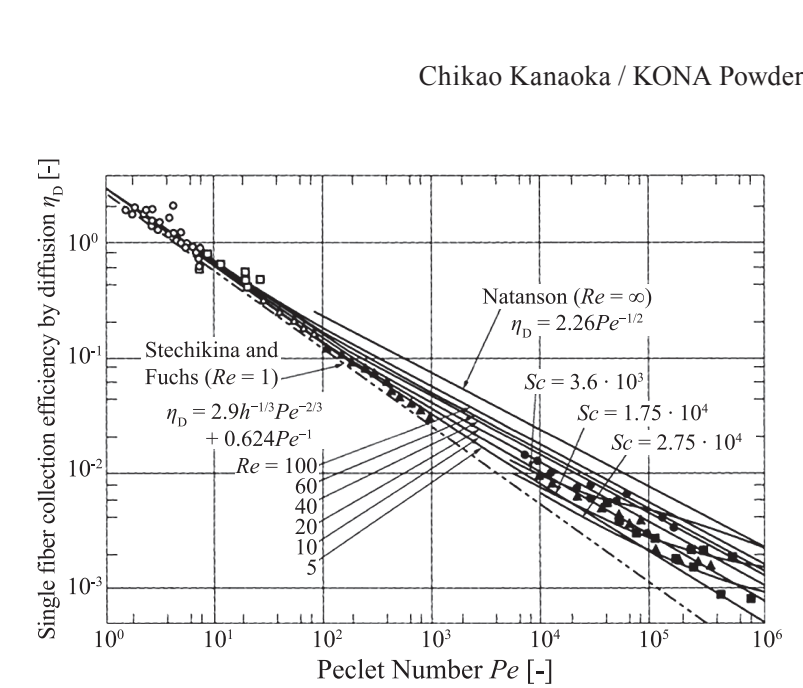

Fig. 5 Single fiber collection efficiency by diffusion. (Modified from Emi H. et al., 1982a)

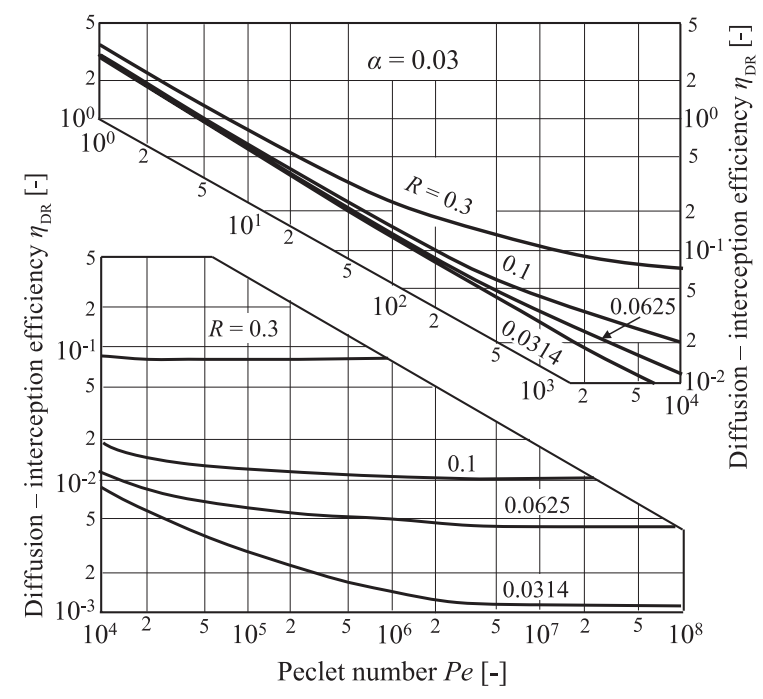

Fig. 6 Single fiber collection efficiency by diffusioninterception. (Modified from Kanaoka C., 1988)

flow (Natanson G. L., 1957b)

$$
\eta_{\mathrm{D}}=2.26 P e^{-1 / 2}
$$

Emi H. et al. (1982a) numerically calculated $\eta_{\mathrm{D}}$ at different $R e$ and $S c$ shown in Fig. 5. It is remarkable that exponent of $P e$ changes from $-2 / 3$ to $-1 / 2$ as $R e$ increases from 0 to infinity, which coincides with exponents in Eqns. (21) and (23). Ingham D.B., (1981) also obtained similar result.

Collection efficiency for $R \neq 0, \eta_{\mathrm{DR}}$ is very different from $\eta_{\text {D }}$ (Lee K.W. and Liu B.Y.H., 1982; Kanaoka C., 1988). Fig. 6 shows the calculated $\eta_{\mathrm{DR}}$ for various $R$ (Kanaoka C., 1988). As seen from the figure, $\eta_{\mathrm{DR}}$ increases with decreasing $P e$ and becomes constant for each $R$ at large $P e$. Pich J. (1966), Smutek M. (1972), Kirsh A.A. et al. (1973), Van Osdell D. et al. (1990), Shapiro M. et al. (1991) discussed the effect of gas slip near a fiber.

Dahneke B. (1971) suggested the possibility of thermal

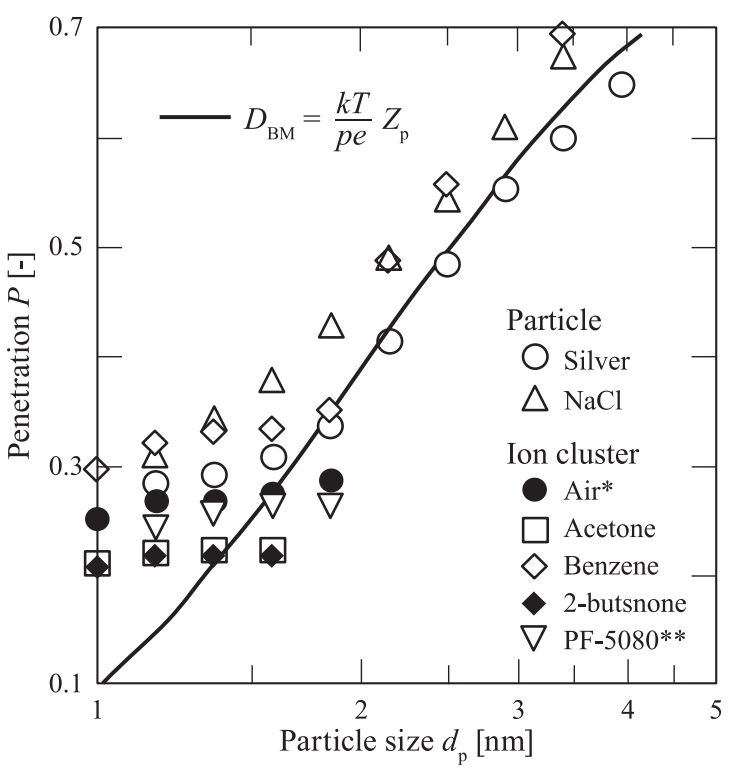

Fig. 7 Penetration of ultrafine particles and ion clusters through wire screens. (Modified from Ichitsubo H. et al., 1996)

* "air" refers the ions generated when no organic impurity was added to the air;

** PF-5800 is a mix of perfluoro compounds, comprising primarily compounds with 8 carbons, manufactured by $3 \mathrm{M}$.

rebound of nanoparticles. Wang H. and Kasper G. (1991) have developed a theory predicting a thermal rebound of particles smaller than $10 \mathrm{~nm}$, it has been examined theoretically and experimentally.

Theoretically, it has been discussed from coefficient of restitution and adhesion energy (Sato S. et al., 2007; Mouret G. et al., 2011) and Givehchi R. and Tan Z. (2014) discussed the effect of capillary force and existence of a thermal rebound but it has not been clearly demonstrated the existence of a thermal rebound.

Experimentally it has been examined by various combinations of particles (material and size), collection media (material, fiber diameter) and operation conditions many researchers such as Scheibel H.G. and Porstendörfer J. (1984), Van Osdell D.W. et al. (1990), Otani Y. et al. (1995), Skaptsov A.S. et al. (1996), Ichitsubo H. et al. (1996), Wang H.-C. (1996), Alonso et al. (1997), Kim C.S. et al. (2006), Kim S.C. et al. (2007), Japuntich D.A. et al. (2007), Steffens J. and Coury J.R. (2007a, b), Wang J. et al. (2007), Heim M. et al. (2005, 2010), Podgórski A. et al. (2006), Huang S. et al. (2007), Rengasamy S. et al. (2008), Shin W.G. et al. (2008), Golanski L. et al. (2009), Van Gulijk C. et al. (2009), Yamada S. et al. (2011). Reduction of efficiency was observed below $2 \mathrm{~nm}$ by only a few experiments. Fig. 7 shows the experimental penetration by Ichitsubo et al. (1996). Givehchi R. and Tan Z. (2014, 2015) precisely reviewed the thermal rebound. 


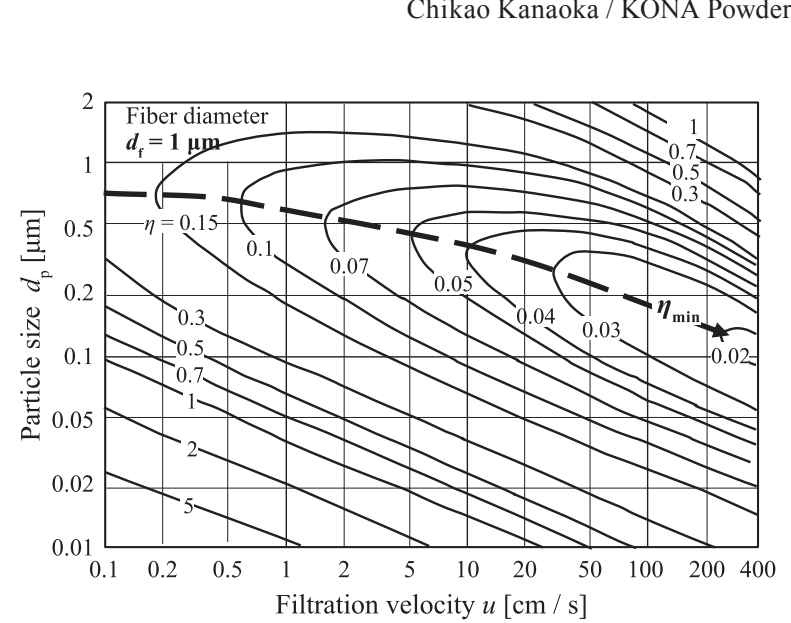

(a) $\eta_{\text {IDGR }}$ for fiber diameter of $1 \mu \mathrm{m}, \alpha=0$

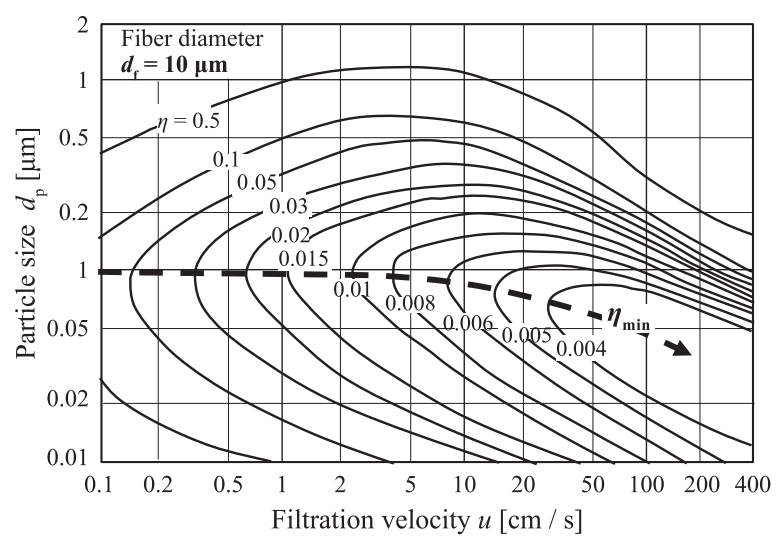

(b) $\eta_{\mathrm{IDGR}}$ for fiber diameter of $10 \mu \mathrm{m}, \alpha=0$

Fig. 8 Contour chart of total collection efficiency. (Modified from Emi H. et al., 1973)

\subsubsection{Total collection efficiency by mechanical effects $\eta_{\text {IDGR }}$}

In the actual filtration, every mechanism contributes to the capture of particle simultaneously. Hence collection efficiency taken account of all mechanisms has to be used for the estimation of actual filtration. Emi et al. estimated $\eta_{\text {IDGR }}$ for an isolated fiber by taking account of the contribution of individual efficiency at given filtration condition.

Fig. 8(a) and (b) shows the predicted contour charts for fiber diameter of 1 and $10 \mu \mathrm{m}$ (Emi H. et al., 1973). In the figure, each line is the line of equal collection efficiency and efficiency of contour line gets small from outside to inside. Furthermore, $\eta_{\text {IDGR }}$ has a minimum efficiency $\eta_{\text {min }}$ against filtration velocity $u$ and particle size, $d_{\mathrm{p}}$ by keeping $d_{\mathrm{p}}$ and $u$ constant, respectively. $\eta_{\min }$ appears at the transition region of two collection mechanisms and shifts to higher $u$ and lower $d_{\mathrm{p}}$, shown by the dashed arrow lines in both figures.

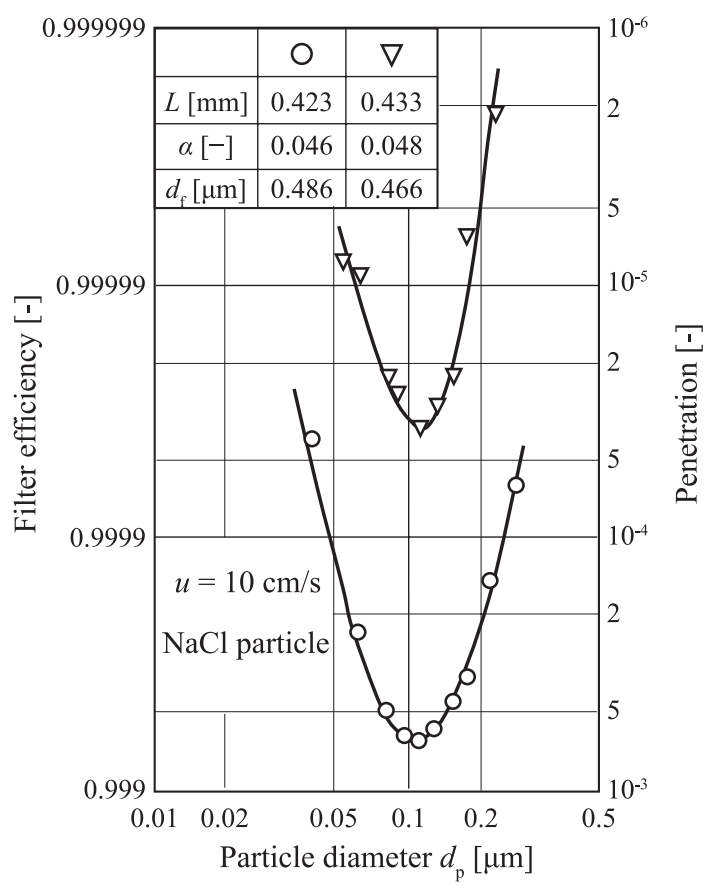

Fig. 9 Filter efficiency and penetration of HEPA filter. (Modified from Emi H. and Kanaoka C., 1981; Emi H. et al., 1982b)

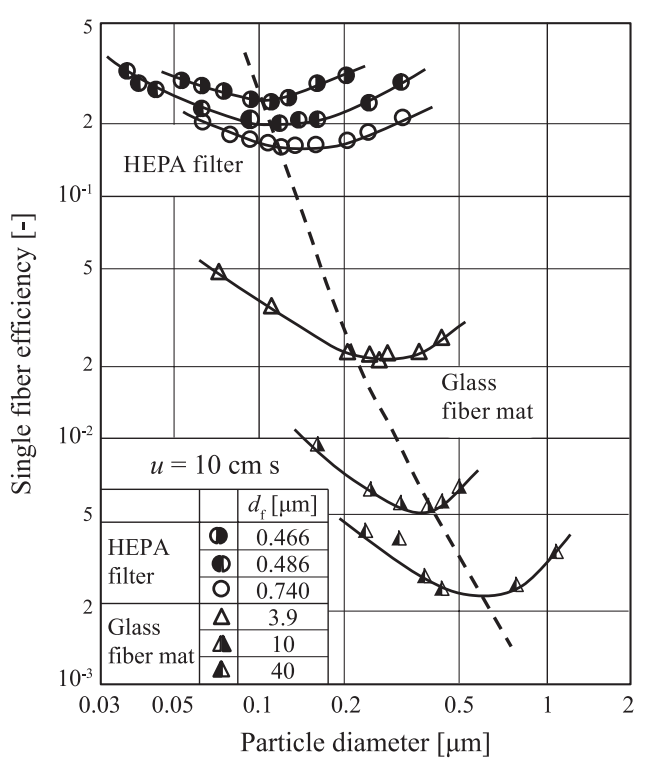

Fig. 10 Experimental single fiber collection efficiency $\left(\alpha_{\mathrm{f}} \cong\right.$ 0.05). (Modified from Emi H. et al., 1982b)

\subsection{Filter efficiency}

\subsubsection{Particle size at minimum collection efficiency (MPPS)}

As described above, $\eta$ has minimum at certain filtration condition. This is especially important for high performance air filter like HEPA and ULPA filter. Fig. 9 shows filter efficiency of two HEPA filters against particle size (Emi H. and Kanaoka C. 1981; Emi H. et al., 1982b). In 


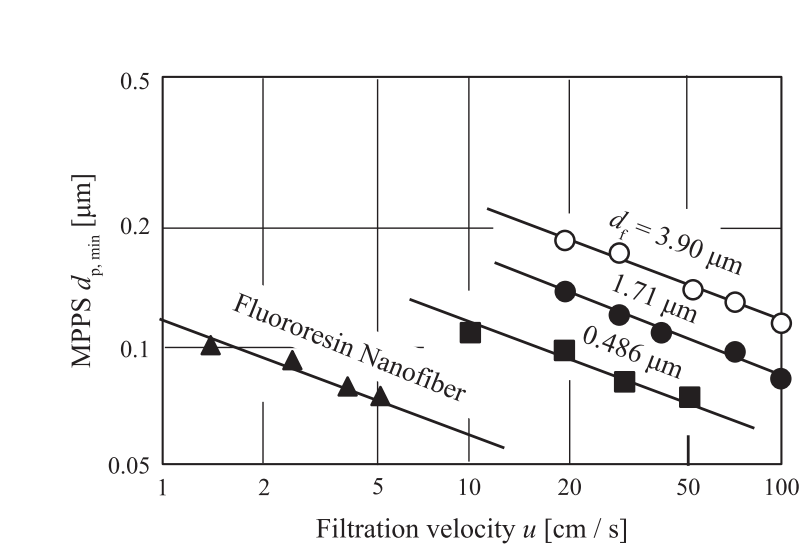

Fig. 11 Correlation of MPPS with filtration velocity. (Data from Emi H. et al., 1982b and Bao L. et al., 2015)

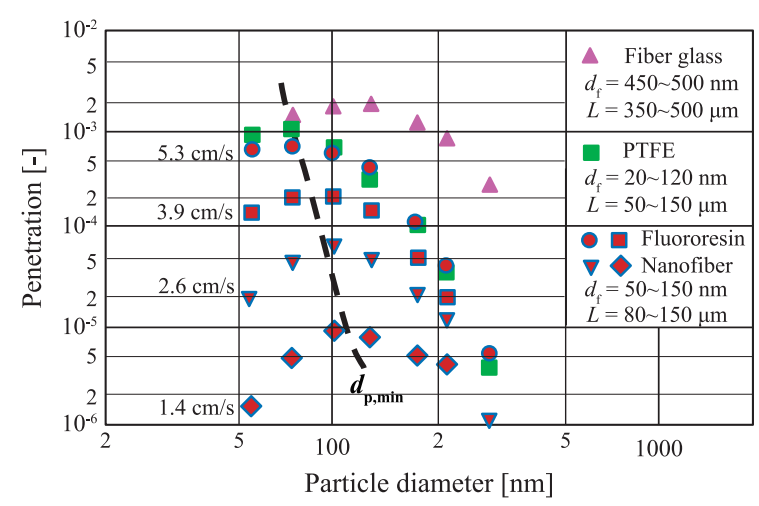

Fig. 12 Penetrations of nanofiber and ordinary HEPA filters. (Modified from Bao L. et al., 2015)

the figure, collection efficiency is higher than $99.9 \%$ at any particle size and minimum efficiency appears around $0.1 \mu \mathrm{m}$ and both penetrations differs more than an order of magnitude. Particle size at minimum collection efficiency (MPPS) is an important indicator of air filter since single fiber efficiency at MPPS is the lowest and thus the filter efficiency is higher than that at MPPS. Fig. 10 shows behaviour of collection efficiency near MPPS of HEPA and fibrous mat filters (Emi H. et al., 1982b) and Fig. 11 is an experimental correlation of MPPS with filtration velocity and fiber diameter. As seen from the figures, MPPS decreases as filtration velocity and fiber diameter decrease. Stechkina I.B et al. (1969), Wake D. (1989), Dhaniyala S. and Liu B.Y.H. (1999a, b), Podgórski A. et al. (2006) reported MPPS by different type of filters and particles.

Nanoparticle collection is an important issue. Hunt B. et al. (2014) calculated a single fiber collection efficiency of nanoparticles based on a mean first-passage time method. Wang J. et al. (2008a, b) demonstrated the superiority of a single layer nano-fiber filter against ordinary filter below $100 \mathrm{~nm}$ because of slip flow. Gopal R. et al.(2006), Yoon K. et al.(2006), Yun K.M. et al.(2007), Ma H. et al. (2010), Podgorski. A. et al. (2011), Kuo Y.Y. et al.

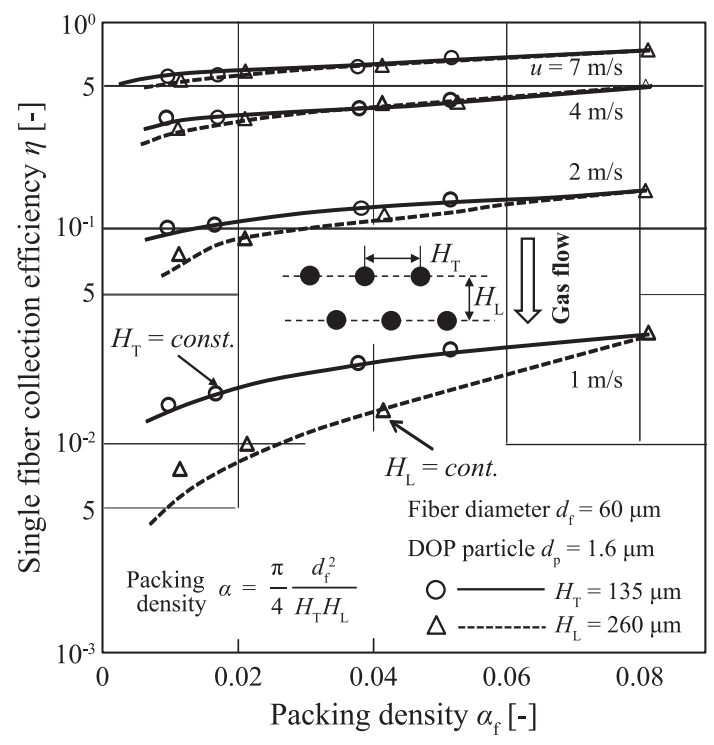

Fig. 13 Effect of inter-fiber distance on single fiber collection efficiency. (Kanaoka C. et al., 1984a)

Test filter PTFE non-circular fiber, $d_{\mathrm{f}}=13.7 \mu \mathrm{m}$, mean fiber, Test particle: Atmospheric particle $d_{\mathrm{p}}=$ $0.3 \sim 0.5 \mu \mathrm{m}$, mass $700 \pm 70 \mathrm{~g} / \mathrm{m}^{2}$, mean permeability $15 \pm 5 \mathrm{~cm} / \mathrm{s}$

Dust concentration measurement by Digital dust counter

Size of one cell in the figure: $7 \mathrm{~cm} \times 7 \mathrm{~cm}$

(2014), Kao T.-H. et al. (2016) tested by spunbond nano filters. Bao L. et al. (2015) compared the penetrations of nanofiber filter and HEPA filters shown in Fig. 12. Their MPPS is also plotted in Fig. 11 appearing smaller than ordinary filter. It decreases with filtration velocity and is almost parallel with previous result.

\subsection{Effects of filter structure, particle shape, fiber shape on filter performance}

In actual filtration, filter and particles are very different from ideal. Effects of fiber size distribution were studied by Kirsh A.A. et al. (1975, 1978), Brown R.C. et al. (1987), Brown R.C. and Thorpe A. (2001). Concerning the effect of fiber orientation and packing was done by Overcamp T.J. (1985), Otani Y. et al. (1998), Bao L. et al. (1998), Dhaniyala S. and Liu B.Y.H. (2001), Endo Y. et al. (2001), Steffens J. and Coury J.R. (2007b), Mouret G. et al. (2009), Podgorski A. et al. (2009, 2011), Hunag S.-H. et al. (2010), Fotovati E. et al. (2010), Yamada S. et al. (2011), Eryu K. et al. (2011), Soltani P. et al. (2014), Shou D. et al. (2015), Kanaoka C. et al. (1984a, 2016, 2017).

Fig. 13 shows the effect of neighboring fiber on $\eta$ in a parallel arrayed model filter by Kanaoka C. et al. (1984a). $\eta$ for constant $H_{\mathrm{T}}$ is higher than that for constant $H_{\mathrm{L}}$, suggesting $H_{\mathrm{T}}$ affects efficiency more than longitudinal interval. 


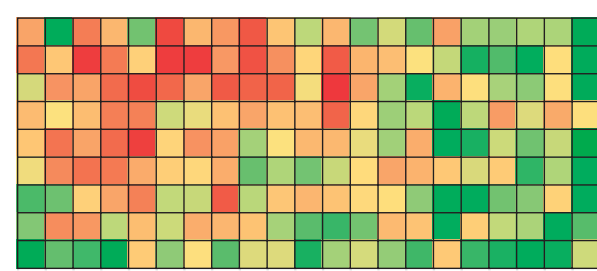
low

large

(a) Mass distribution

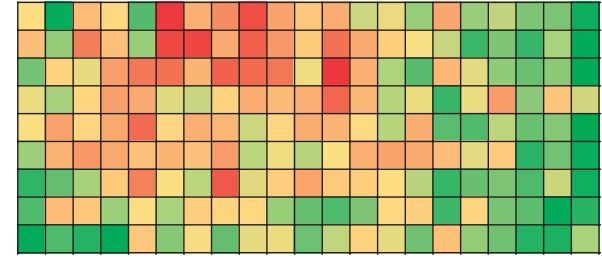

low large

(c) Emission for $u=1 \mathrm{~m} / \mathrm{min}$

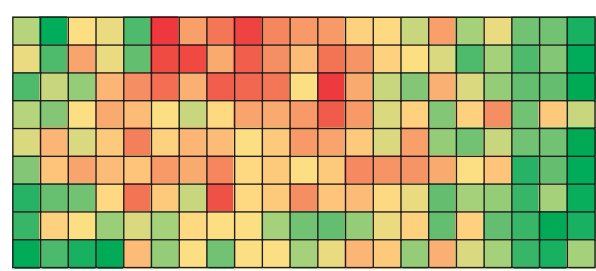

low

(b) Permeability distribution

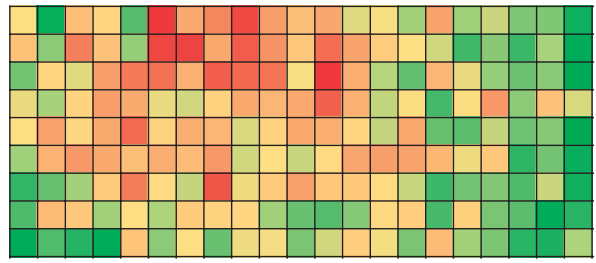

low large

(d) Emission for $u=2 \mathrm{~m} / \mathrm{min}$

Fig. 14 Distributions of fiber mass, permeability and particle emission from fibrous filter with $63 \mathrm{~cm} \times 147 \mathrm{~cm}$.

(Kanaoka C. et al., 2016, 2017)

Fig. 14 shows the experimental distribution of fiber mass, permeability and particle emission at filtration velocities of 1 and $2 \mathrm{~m} / \mathrm{min}$ of PTFE filter media with $63 \mathrm{~cm} \times 147 \mathrm{~cm}$. They were measured $7 \mathrm{~cm} \times 7 \mathrm{~cm}$ cells. In the figure (a), cell with reddish color indicates smaller fiber mass and greenish larger mass. Contrarily reddish color in figures (b), (c) and (d) indicates high or large and greenish low or small. Their color distribution coincides with each other. This means that smaller is the fiber mass, higher and larger are permeability and particle emission from the filter.

On the influence of fiber shape, Kimura N. and Iinoya K.(1969a), Inagaki M. et al. (2001), Wang W. et al. (2012), Wang K. and Zhao H. (2015), Zhu C. et al.(2000). Boskovic L. et al. (2005, 2007, 2008), Jin X. et al. (2017) investigated for various shapes of fibers.

\subsection{Single fiber collection efficiency by electrostatic effect}

Collection performance by electrostatic effects depends on the charging states of particle and fiber and existence of external electric field.

For no external electric field, collection of charged particles by charged fibers was studied by Kraemer H.F. and Johnstone H.F. (1955), Yang S. and Lee' G.W.M.(2005), and charged particles by uncharged fiber by Natanson G.L.(1957a), Lundgren D.A. and Whitby K.T. (1965), Yoshioka N. et al. (1968), Takahashi T. and Kanagawa A. (1975).

For the case of existence of electric field, collection of uncharged particles was studied by Zebel G. (1965), Iinoya K. et al. (1965), Kirsch A.A. (1972), Takahashi T.

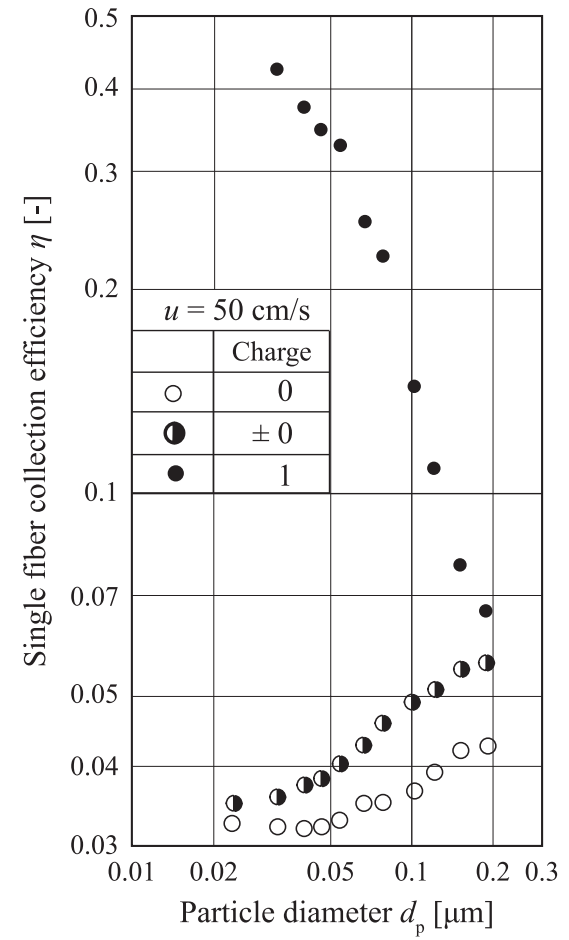

Fig. 15 Single fiber collection efficiency of particles at different charging state by an electret fiber (Modified from Emi H. et al., 1987)

and Kanagawa A. (1978), Makino K. and Iinoya K. (1968, 1969a), and charged particles by Zebel G. (1965), Takahashi T. and Kanagawa A. (1978), Zhao Z.-M. (1991), Pnueli D. et al., (2000) and Sanchez A.L. et al. (2013).

After Turnhout J.V. (1976) invented an manufacturing method of electret filter, electret fibrous filter has been used popularly as a high performance air filter. Investiga- 
tion about its collection mechanisms has been carried out from various view points such as collection mechanisms by Emi H. et al. (1987), Pich J. et al. (1987), Romay F.J. et al (1998), filtration performance of various particles by Baumgartner H.-P. and Löffler F. (1986), Kanaoka C. et al., (1987), Otani Y. et al. (1992, 1993), Kim J. et al. (2009), Chazelet S. et al. (2011), effect of charging process and collection performance by Nifuku M., et al. (2001), Kawabe M. et al. (2009), Choi H.-J. et al. (2015), Kilic A. et al. (2015). Time change of electret fiber was investigated by Kanaoka C. et al. (1984b), Lee M., et al. (2002), Choi H.-J. et al. $(2014,2015)$ and electrification method and process was by Kawabe M. et al. (2009), Kilic A. et al. (2015).

Fig. 15 shows $\eta$ at different charging states by a rectangular electret fiber (Emi H. et al., 1987). As seen from the figure, since charged particle is captured by Coulomb force, $\eta$ is very high at small particle and decreases with particle size becomes large. For non-charged and Boltzmann equilibrium particles, they are collected by induced force so that $\eta$ is low at small size and increases with particle size.

\section{Particle collection at Stage 2}

Once particle is captured, gas flow in the vicinity of the fiber changes and thus filter performance such as filter efficiency and pressure drop changes with time.

This type of particle collection is utilized mainly in the field of air filtration such as for the creation of highly purified space, ventilation of air and intake air cleaning for internal combustion air and so on.

For the case of collection of solid particles by a fibrous filter, Yoshioka N. et al. (1969b), Kimura N. et al. (1969b, c, 1970, 1985, 1989), Davies C.N. (1970), Kanaoka C. et al. (1980a), Hinds W.C. and Kadrichu N.P. (1997), Bémer D. and Callé S. (2000), Sakano T. et al. (2000), Wang Q. et al. (2016), Hasolli N. et al. (2013a, b) measured evolution of filter performance and analyzed the phenomena based on the measurements.

Yoshioka N. et al. (1969b) applied analysis method of clarifying filtration and obtained analytical expressions for filter efficiency and dust load as,

$$
\begin{aligned}
& E=1-\frac{\exp \left(-\lambda A C_{\mathrm{in}} u t\right)}{\exp \left(-\lambda A C_{\mathrm{in}} u t\right)+\exp (A L)-1} \\
& m=-\frac{1}{A} \frac{\exp \left(-\lambda A C_{\mathrm{in}} u t\right)}{\exp \left(-\lambda A C_{\mathrm{in}} u t\right)+\exp (A L)-1} \\
& A=\frac{4 \alpha \eta_{\mathrm{m}}}{\pi(1-\alpha) d_{\mathrm{f}}}
\end{aligned}
$$

In the derivation, they assumed collection efficiency of dust loaded fiber $\eta_{\mathrm{m}}$ as,

$$
\eta_{\mathrm{m}}=\eta_{0}(1+\lambda m)
$$

Their experimental result was explained by Eqns. (25) and (26) assuming $\lambda=5 \mathrm{~m}^{3} / \mathrm{kg}$.

Clogging of nano-size particles in HEPA filter was carried out concerning effect of gas slip (Leung W.W.-F. and Hung C.-H. 2008, 2009), particle distribution (Brourrous S. et al., 2014), structure and loading capacity (Contal P. et al., 2004; Kim S.C. et al., 2009), liquid and humidity, hygroscopicity (Payet S. et al.,1992; Contal P. et al., 2004; Gupta A. et al., 1993; Joubert A. et al., 2010; Agranovski I.E. and Shapiro M., 2001) and etc.

Measurements for the case of electret filter were carried out by Baumgartner H.-P. and Löffler F. (1986, 1987), Brown R.C. et al. (1988), Hiragi S. et al. (1990b), Stenhouse J.I.T. et al. (1992), Walsh D.C. and Stenhouse J.I.T. (1996, 1997a, b), Janssen L.L. et al. (2003), Ji J.H. et al. (2003), Yang S. et al. (2005), Yang S. and Lee' G.W.M. (2005), Huang B. et al. (2006), Yang S. et al. (2007), Ardkapan S.R. et al. (2014), Xiao H. et al. (2014). They found a unique collection behavior relating to deterioration of electrostatic effect with dust load and recovery of collection efficiency afterwards, and discussed influences by various parameters.

At very initial stage, collected particles form dendritic
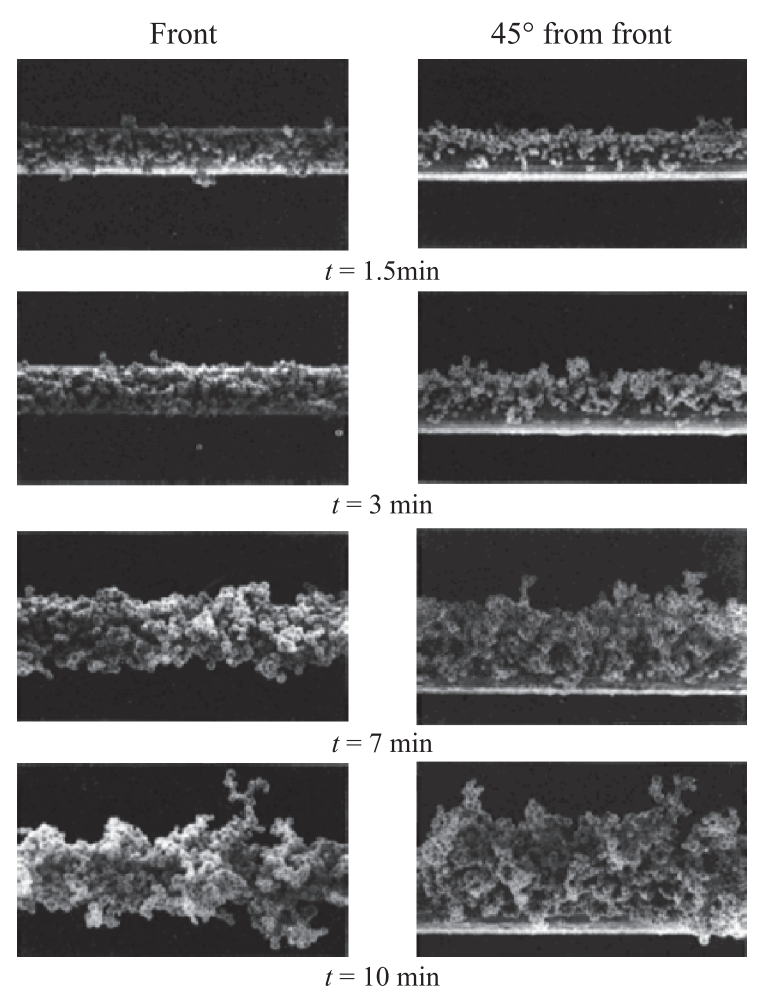

Fig. 16 Time change of particle deposit on a fiber. $d_{\mathrm{f}}=10 \mu \mathrm{m}, d_{\mathrm{p}}=1 \mu \mathrm{m}, \rho_{\mathrm{p}}=11.34 \mathrm{~g} / \mathrm{m}^{3}$ $u=50 \mathrm{~cm} / \mathrm{s}, S t k=3.5, R=0.1$ (Kanaoka C. et al., 1986). 


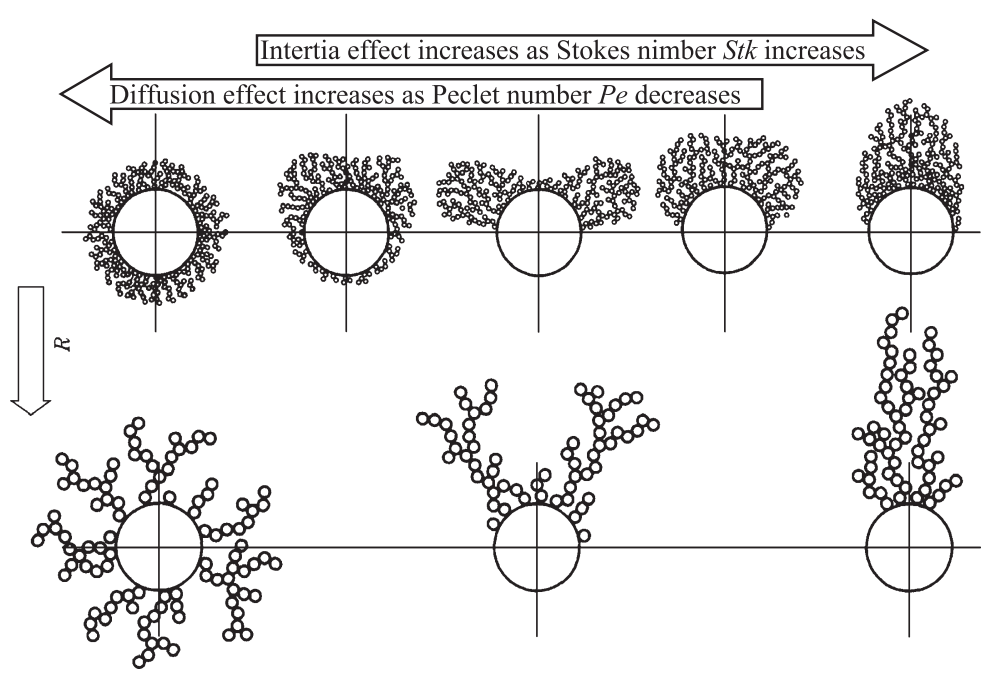

Fig. 17 Morphology of particle deposit by mechanical effects. (Modified from Kanaoka C. et al., 1982)

deposit on a fiber because of hindering effect. Accumulation of solid particles on a fiber was observed by Billings C.E. (1966), Bhutra S. and Payatakes A.C. (1979), Kanaoka C. et al. (1982) observed dendritic growth, Myojo T. et al. (1984), Kanaoka C. et al. (1982, 1986, 1990), Hiragi S. et al. (1990a, b), Song C.B. et al. (2006), Kasper G. et al. (2010), Müller T.K. et al. (2014a, b) observed and discussed the effect of re-entrainment of particles.

Fig. 16 shows the time change of accumulation of $1 \mu \mathrm{m}$ particles collected on a $10 \mu \mathrm{m}$ cylindrical tungsten wire. As seen from the figure, amount of collected particles increases with time so rapidly. Although particles are collected by very strong inertia effect such as $S t k=3.5$ and then particles accumulated on the front surface, morphology of particle deposit changes with filtration condition as shown in Fig. 17. In the figure, deposition pattern at $P e=0$ and $S t k=\infty$ is drawn from theoretical consideration such as distributed uniformly around the fiber for $P e=0$ and sine curve shape in the front side of the fiber for $S t k=\infty$, respectively.

When particles are captured by inertia and/or interception effect, they accumulate on the front side of the fiber but for the case of diffusion, some of them will be collected in the rear side of the fiber. In general, collected particles form porous accumulates and they become coarser with $R$.

Payatakes A.C. (1976a, 1977), Payatakes A.C. and Tien C. (1976b), Payatakes A.C. and Gradoń L. (1980), Payatakes A.C. and Okuyama K. (1982) proposed a deterministic model of the formation of chain-like particle agglomerates on a fiber by interception and inertia effects.

Kanaoka C. et al. proposed a stochastic model of the formation of dendrites by interception (1978), inertia (1980b), diffusion $(1982,1983)$ and electrostatic force (2001). Bahners T. and Schollmeyer (1986), Cai J. and

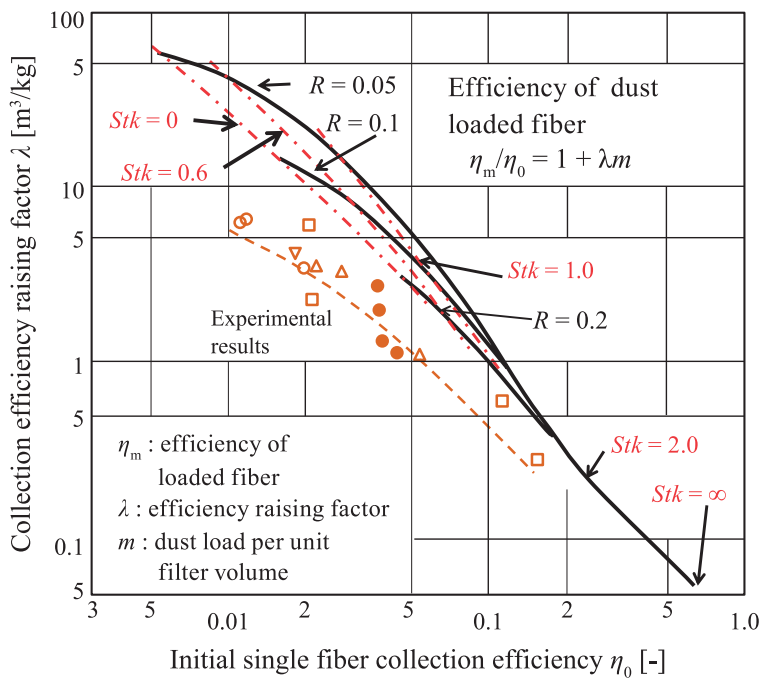

Fig. 18 Simulated and experimental collection efficiency raising factor (Modified from Myojo T. et al., 1984)

Peterson F. (1989a, b), Wongsri M. et al. (1991), El-shobokshy M.S. et al. (1994), Tanthapanichakoon W. et al. (2003), Sae-lim W. et al. (2006) also simulated the filtration process by different collection mechanism and different fiber property and structure by Monte Carlo simulation method. Schmidt E. (1996) simulated 3D dust structures formation, Karadimos A. and Ocone R. (2003) took into account the effect of change of the flow field by dust loading and develop CFD simulation code, Wang $\mathrm{H}$. et al. (2013) and Przekop R. et al. (2003) used Lattice-Boltzmann two-phase flow model for simulation. Li S.Q. and Marshall J.S. (2007) simulated by DEM based on JKR theory for adhesive elastic contacts, Qian, F. et al. (2013) used CFD-DEM, Dunnett S.J. and Clement C.F. (2006, 2012) used boundary element model (BEM).

Kanaoka C. et al. $(1978,1982,1983)$ obtained linear expression same as Eqn. (28) from simulation and experi- 
ndents but value of $\lambda$ was found as a function of filtration candition as shown in Fig. 18.

Kasper G. et al. (2009) proposed a power law expression for packing density $\alpha<0.04$ as,

$$
\eta_{\mathrm{m}}=\eta_{0}\left(1+b m^{c}\right)
$$

In the above equation, $b$ and $c$ are empirical fit coefficients. The exponent $c$ is on the order of $0.7 \pm 0.05$ and approaches to 1 for isolated fiber.

Evolution of pressure drop and holding capacity of particles in the filter is practically important. Medjimorec V. et al. (1981), Japuntich D.A. et al. (1994) estimated the drag forces acting on particle dendrites, Hiragi, S. (1990a), Kanaoka C. and Hiragi S. (1990b) proposed a model to predict pressure drop of dust loaded filter based on the observation of dust captured on parallel arrayed model filter at different times. Joubert A. et al. (2011) proposed a model for the pressure drop across HEPA filters during cake filtration in the presence of humidity. Thomas D. et al. (2014) and Bourrous et al. (2016) derived a model of clogging process of nano-size particles based on precise measurement of porosity and thickness of deposit and deposit distribution in the filter as,

$$
\beta(x)=\frac{m}{S} \cdot \frac{k \exp (-k x)}{\rho_{\mathrm{p}}\{1-\exp (-k x)\}}
$$

Kanaoka C. and Hiragi S. (1990) and Hiragi S. (1990a) proposed to estimate the evolution of pressure drop by a drag theory.

$$
F_{\mathrm{m}}=C_{\mathrm{Dm}} d_{\mathrm{fm}} \frac{1}{2} \rho_{g} u^{2}=\frac{C_{\mathrm{Dm}}}{C_{D 0}} \cdot \frac{d_{\mathrm{fm}}}{d_{\mathrm{f}}} \cdot F_{0}
$$

They determined the evolution of effective fiber diameter $d_{\mathrm{fm}}$ and drag coefficient $C_{\mathrm{Dm}}$ of a fiber by the accumulation of $0.33 \mu \mathrm{m}$ and $0.8-0.84 \mu \mathrm{m}$ on a fiber in a parallel arrayed model filter. Then they confirmed it by the experiments using a fan model filter and glass fibrous mat.

By using their proposal, evolution of filter efficiency, pressure drop and dust load distribution for a uniform filter and a gradient filter having packing gradient in flow direction was calculated. Packing density of both filters was assumed to be $\alpha_{\mathrm{f}, \mathrm{av}}=0.04$ for uniform filter and

Table 2 Calculation conditions

\begin{tabular}{lcc}
\hline Filter thickness & $L$ & $50 \mathrm{~mm}$ \\
Fiber diameter & $d_{\mathrm{f}}$ & $30 \mu \mathrm{m}$ \\
Mean packing density & $\alpha_{\mathrm{f}, \mathrm{av}}$ & 0.04 \\
Particle size & $d_{\mathrm{p}}$ & $0.84 \mu \mathrm{m}$ \\
Particle concentration & $C_{i}$ & $100 \mathrm{mg} / \mathrm{m}^{3}$ \\
Filtration velocity & $u$ & $50 \mathrm{~cm} / \mathrm{s}$ \\
\hline
\end{tabular}

$\left.\alpha_{\mathrm{f}}(x)=0.07(x / L)+0.01\right)$ for gradient filter. Fiber diameter and particle size were set the same as Kanaoka et al. (1990). Non-consolidation of loaded dust due to the pressure drop of filter was assumed. Calculation conditions are listed in Table 2.

Fig. 19 shows the calculated evolution of filter efficiency, $E$ and pressure drop, $\Delta p_{\mathrm{m}}$ of two filters, and loaded mass distributions in Fig. 20.

As seen from Fig. 19, $E$ and $\Delta p_{\mathrm{m}}$ of both filters increase with $C u t$ but $E$ and $\Delta p_{\mathrm{m}}$ of the gradient filter are higher than those of uniform filter from the beginning and reaches $100 \%$ collection efficiency faster. In the figure, pressure drop curve of the uniform filter stops the middle of the graph but that of the gradient filter continues much longer. In this case, gradient filter can operate about 3

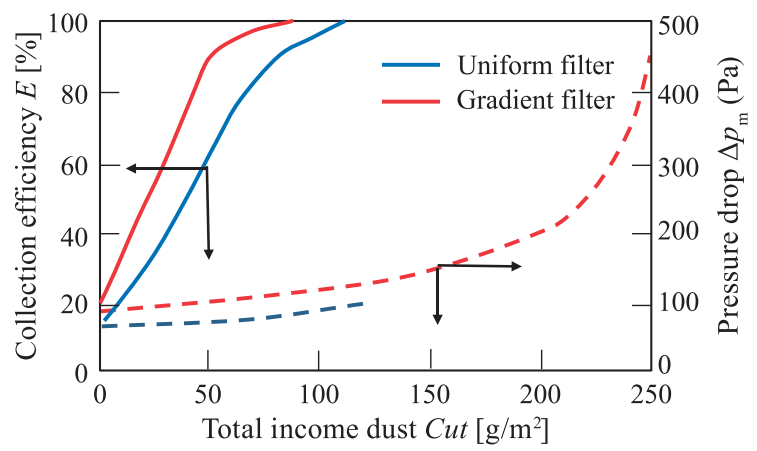

Fig. 19 Comparison of filter efficiency and pressure drop of uniform and gradient filters.

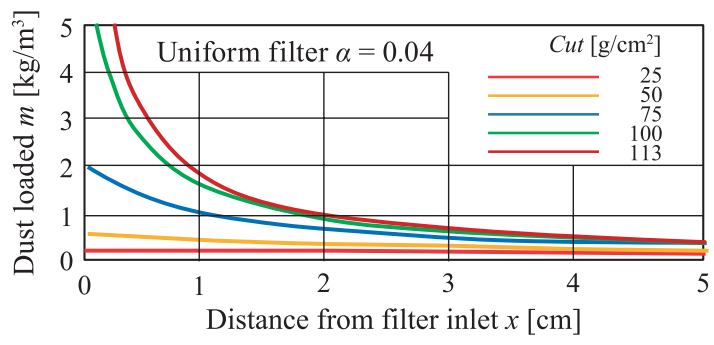

(a) Uniform filter

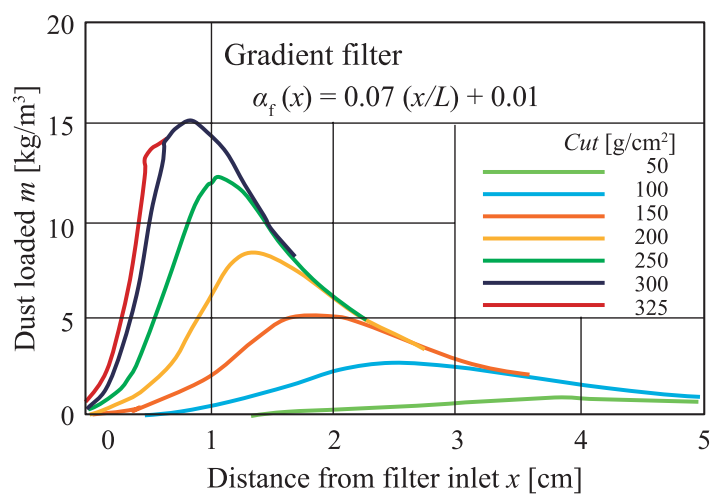

(b) Gradient filter

Fig. 20 Change of dust load distribution of uniform and gradient filters. 
tiones of the uniform filter. This difference is explained by the difference in dust load distribution in the filter, for the case of uniform filter, dust accumulates mainly inlet part, but for the case of gradient filter, maximum load appears at rear part of the filter at beginning and it increases and shifts to front direction with time. Dust holding capacity of the filter can be predicted from distribution curve and expected maximum dust load shown by black and red curves in Fig. 20(b). In this case, holding capacity of the gradient filter is about 3 times larger than the uniform filter. Same change of dust load distribution takes place when fiber has a size distribution in the depth direction. Hence, it can be said that holding capacity and service life time of air filter must be controllable by giving appropriate distribution in fiber packing density and/or size.

\section{Particle collection at Stage 3}

In this stage, particles are at dust cake formed on the filter media almost perfectly, i.e., forthcoming particles will be collected almost perfectly. Bag and cartridge filtration is the technology to utilize this situation. Bag filter is an important technology in the industrial sector. Hence, practical handbook and books have been published such as Billings C.E. and Wider J. (1970), Leith D. et al. (1978), Donovan R.P. (1985), Turner J.H. et al. (1987a, b), Löffler F. et al. (1988), Mukhopadhyay A. (2009a, b).

\subsection{Dust cake formation and related phenomena}

As described above, particles are removed perfectly at dust cake. However, the practical bag filtration is the repetition of filtration and cleaning of dust cake. As a result, grade efficiency $\eta\left(d_{\mathrm{p}}\right)$ of filter changes as shown in Fig. 21. As seen from the figure, $\eta\left(d_{\mathrm{p}}\right)$ is fairly low when the filter is fresh, i.e., never used before, but it becomes $100 \%$ regardless of particle size just before dust cleaning, i.e., filter is covered with dust cake. Furthermore, the filter experienced 5 cleaning operations, $\eta\left(d_{\mathrm{p}}\right)$ just after 5 cleanings is much higher than that of fresh filter at any particle size. This means $\eta\left(d_{\mathrm{p}}\right)$ just after cleaning operation rises a little by the cleaning because of formation of primary dust layer.

After the cleaning operation, large amount of particles are emitted from the filter. Fig. 22 (Yoneda T., 2001) is an example of the time change of exhausted dust concentration from a pilot scale bag filter system. As seen from the figure dust concentration impulsively jumps up and down more than 2 orders of magnitude from basement concentration just after the injection of cleaning pulse air.

Mori Y. et al. (1979) tested 9 different fabrics (fresh and used for each fabric) with 3 different particles and found pressure drop is expressive by the form of $\Delta p \propto u^{n}, n>1$.

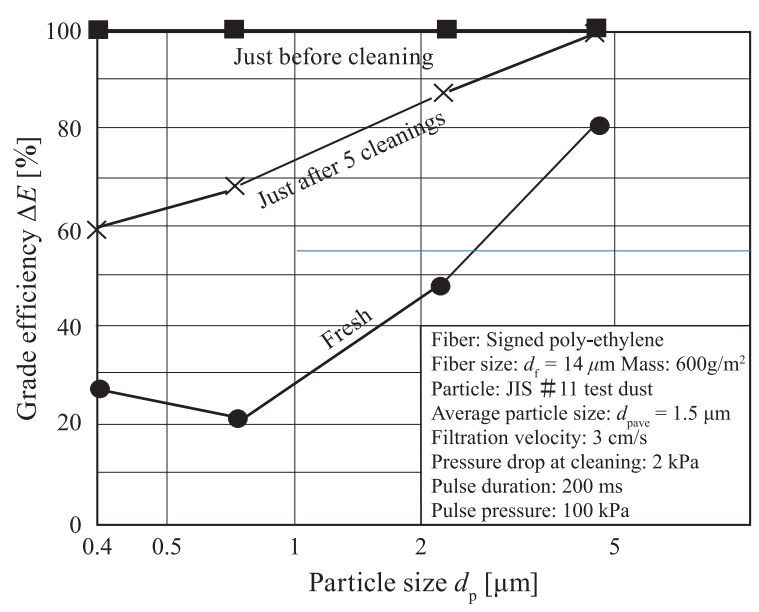

Fig. 21 Grade efficiency of bag filter medium. (Modified from Shin-Kogaiboushi no gijutsutohouki, 2015)

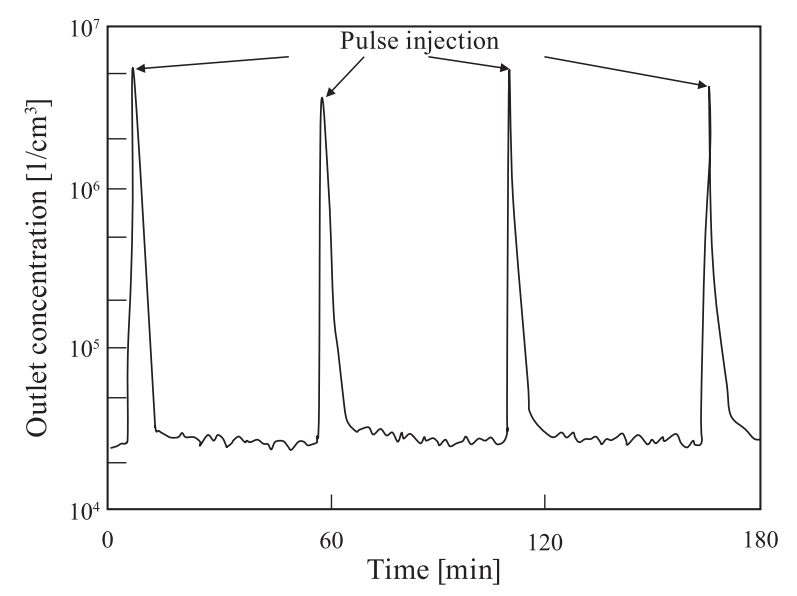

Fig. 22 Time change of emitted dust concentration from a bag filter. (Modified from Yoneda, T., 2001)

Pressure drop and filtration velocity show a hysteresis behavior at same dust load. Leith D.H. et al. (1977a, b) investigated recapturing of removed particles due to the strong back flow phenomenon. Hirota M. et al. (1985, 1987) discussed dust collection from the flowability of dust and Ikeno H. et al. (2009) from pressure drop and filter medium. Koch M. and Krammer G. (2008) discussed the effect of permeability distribution on the filter media characterization.

Yamada M. et al. (1987) estimated the mechanical strength of the dust Layer on bag fabric. Schmidt E. and Löffler F. (1990) observed the cross sectional structure of dust cakes by microscopic examination. Saleem M. et al. (2012) discussed the influence of operating parameters on the cake formation.

Ellenbecker M.J. and Leith D. (1980) obtained the effect of dust retention on pressure drop in a high velocity filter, and Cheng Y.-H. and Tsai C.-J. (1998) investigated factors influencing pressure drop through a dust cake during filtration. Silva C.R.N. et al. (1999) estimated cake/ 

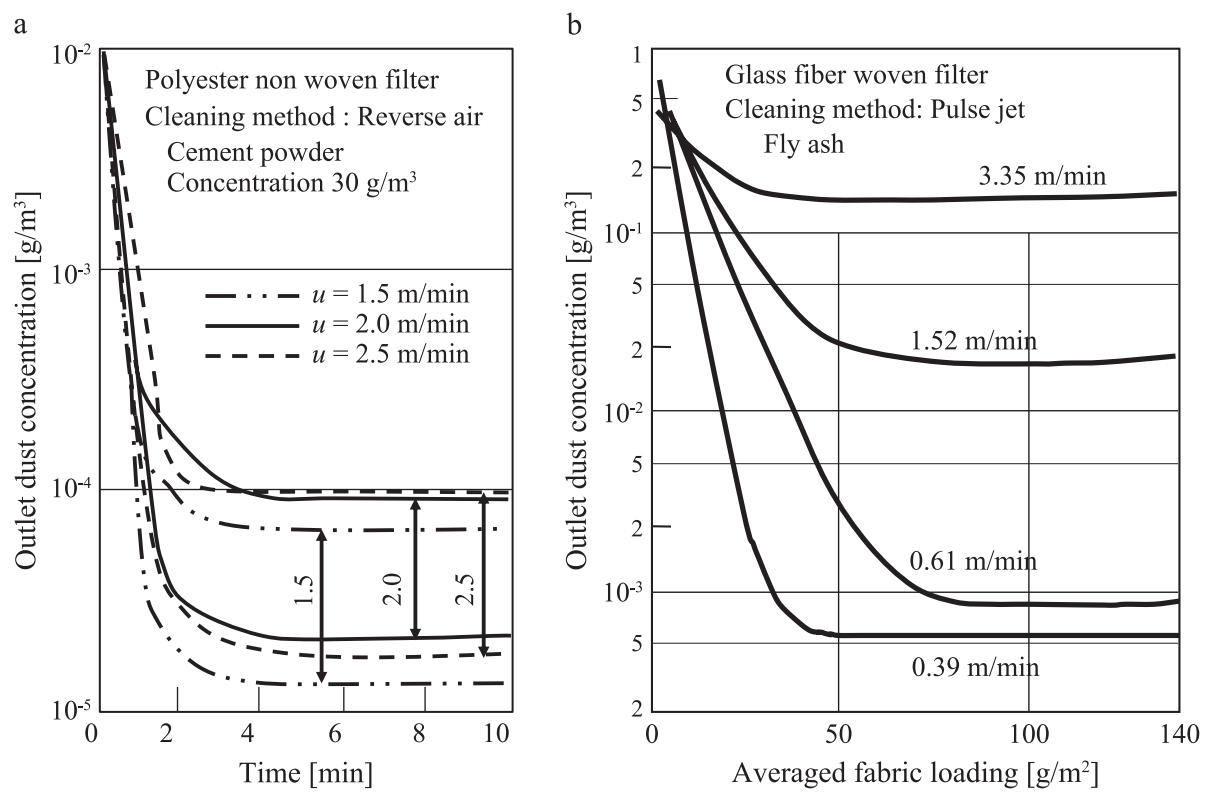

Fig. 23 Outlet dust concentration after cleaning process. (a) Nonwoven filter by reverse air; (b) Woven filter by pulsejet air. (Modified from Yoneda T., 1989; Dennis R. and Klemm H.A., 1979a, b)

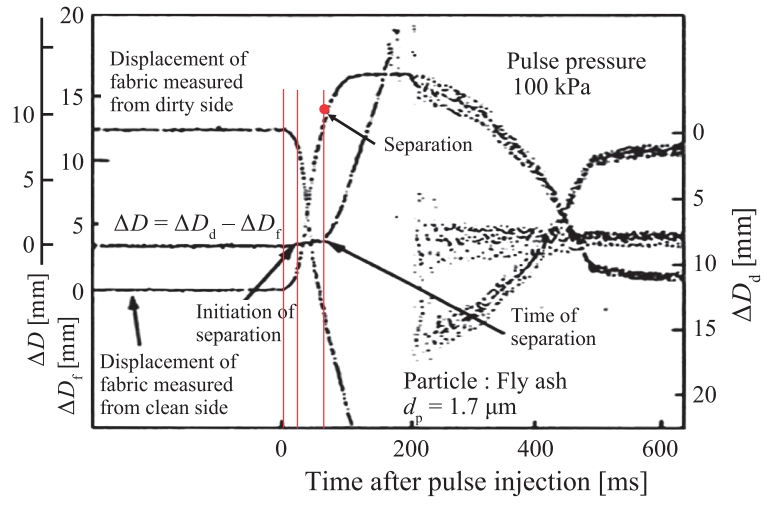

Fig. 24 Initiation and termination of the separation of dust layer. (Modified from Kanaoka C. et al., 1994)

fabric adhesion force from filtration and cleaning measurements.

Fig. 23 shows the detail change of outlet dust concentration after cleaning process at different filtration velocity studied by Yoneda T. (1989) for nonwoven filter and Dennis R. and Klemm H.A. (1979a, b) for woven filter. As seen from the figure, decreasing trends of both filters coincide with each other against time and filtration velocity, i.e., outlet concentration decreases steeply at the beginning and slows down and becomes stable in short time. Furthermore, stabilized concentration is lower as filtration velocity is low, despite of the different weaving and cleaning methods.

Leith D. and Ellenbecker M.J. (1982) measured dust emission characteristics of pulse-jet-cleaned fabric filters. Simon X. et al. (2014) also measured downstream particle puffs emitted during pulse-jet cleaning and investigated the influence of operating conditions and filter surface treatment, Fang C. et al. (2015) studied experimental investigation on particle entrainment behavior near a nozzle in gas-particle coaxial jets.

\subsection{Cleaning of dust cake on the filter medium}

Cleaning of dust cake is one of the most important processes. During filtration period, filter is pressed toward inside. When high pressure compressed gas is injected from the open end of the filter bag for a short time, it expands toward outside.

According to this filter movement, dust cake moves with filter but it is removed just before filter full expanded state of filter. This situation is shown in Fig. 24 observed by the plane type fabric test rig (Kanaoka C. et al., 1994). In the figure, $\Delta D_{\mathrm{f}}$ and $\Delta D_{\mathrm{d}}$ stand, displacements measured from clean side and dirty side, respectively. $\Delta D$ is defined as $\Delta D=\Delta D_{\mathrm{d}}-\Delta D_{\mathrm{f}}$ and means the relative displacement of dust cake, i.e., when $\Delta D=0$, dust cake moves with filter but $\Delta D>0$, dust cake movement is different form filter motion, i.e., dust cake is removed from the filter. In the figure, after cleaning air is injected, $\Delta D_{\mathrm{f}}$ increases and $\Delta D_{\mathrm{d}}$ decreases. This means filter expands outward and filter and dust cake move together at very beginning (between left to middle red lines). Then dust cake moves slightly different from filter with time (between middle to right red lines). Finally, $\Delta D$ becomes large rapidly showing the separation of dust cake, which happens at red circle in the figure.

Dennis R. and Klemm H.A. (1980) and Dennis. R. et al. (1981) gave modelling concepts for pulse jet filtration 
and then analysed the pressure loss for pulse jet filters from the relationship between dust adhesion to the fabric and the opposing force. Leith D. and Ellenbecker M.J. (1980) also presented a theory for pressure drop in a pulse-jet cleaned fabric filter.

Iinoya K. et al. (1979) measured dust dislodging performance of a pulse-jet fabric filter. Humphries W. (1981) investigated the influence of cloth structure on dust dislodgement from fabric filters and discussed the relationship between residual dust load and the structure of filter medium. Kanaoka C. et al. (1994) investigated dust cleaning mechanism of a pulse jet type bag filter. Kanaoka C. and Yao Y. (2003) studied time dependency of the pressure drop in a flat type pulse jet fabric filter. Ikeno H. et al. (2004) studied pressure drop in bag filter based on patched cleaning model, Simon X. et al. (2007) experimentaly studied parameters affecting pulse-jet cleaning of bag filters supported by rigid rings. Binnig J. et al. (2011) analysed the cleaning pulse intensity in a surface filter test rig by dimensionless analysis method. Yao Y. et al. (2008) and Mao N. et al. (2008) compared the filter cleaning performance between VDI and JIS testing rigs for cleanable fabric filter. Qian Y. et al. (2015) investigated the effect of filtration operation and surface treatment on pulse-jet cleaning performance of filter bags. Ellenbecker M.J. and Leith D. (1983) measured dust removal characteristics of 3 fabrics with different surface treatment. Makino K. et al. (1976) and Ikazaki F. et al. (1978) studied dislodgement of dust cake by electrostatic effect. Tsubaki J. et al. (1982) and Naito, M. et al. (1984) studied dislodgement of deposited dust layer by applying normal stress. Park B.H. et al. (2010) proposed a preparation and characterization method of porous composite filter medium by polytetrafluoroethylene foam coating to improve separation performance.

\subsection{Improvement of system performance}

Since bag filter system is composed of many filter elements, its performance depends not only on the performance of individual filter but also on the system design and operation mode.

Fig. 25 schematically shows (a) the changes of system parameters and (b) phenomena taking place in a bag filter system with 3 pulse cleaning blocks. (a) shows the time changes of parameters such as pressure drop of filter system $\Delta p$, dust load on a bag filter element in within each cleaning block $m_{i}$ and emitted dust concentration from the filter system $C_{o}$, respectively. Pressure drop of the system drops when cleaning pulse is injected and increases with time until next cleaning operation so that it changes in zig zag shape with time but does not change so much. Concerning dust load $m_{i}$, by the cleaning operation at block 1 , $m_{1}$ immediately drop down to almost zero but $m_{2}$ and $m_{3}$

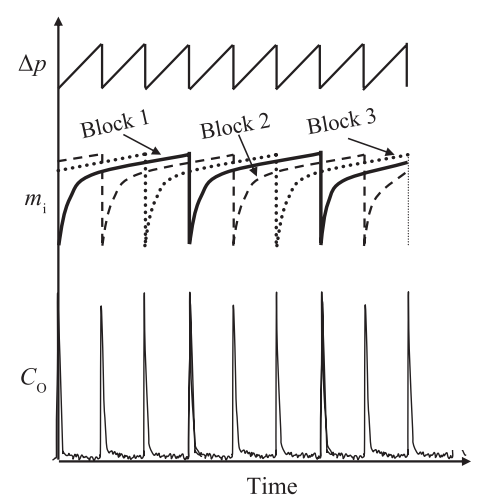

(a) Time changes of pressure drop, dust load and outlet dust concentration

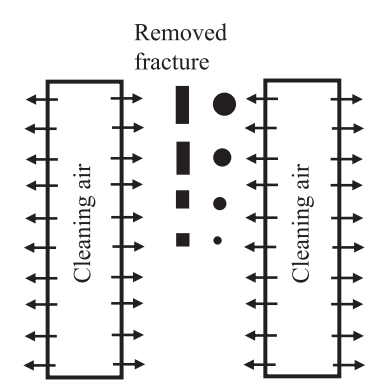

(b) Just after cleaning

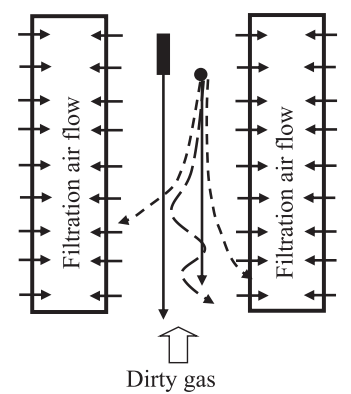

(c) Restart of filtration
Fig. 25 Conceptional expression of system parameters.

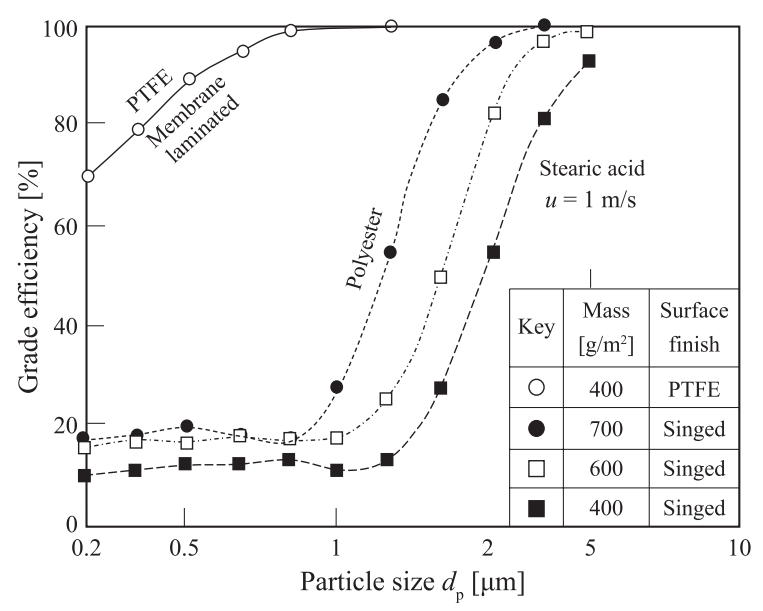

Fig. 26 Comparison of filter efficiency of different fiber mass and surface treatment for polyester filter media. (Modified from Hakamata T. et al., 1993)

stay fairly high values and then flow resistance of bag filters in block 1 decreases by the clean operation, $m_{1}$ increases quickly because of the concentration of gas flow to block 1 but dust load of other two blocks $\boldsymbol{m}_{\mathbf{2}}$ and $\boldsymbol{m}_{\mathbf{3}}$ do not change so much. Outlet is concerned, it jumps up at every cleaning process but drops down to very low level quickly and keeps almost the same level until next cleaning operation. (b) and (c) show the phenomena taking place in the filter system accompanying to the cleaning 
profess. i.e., (b) shows the phenomena when cleaning campressed air is injected and (c) represents the situation just after filtration restarted. Since time interval between cleaning operation and restart of filtration is very short, removed dust has to fall down to the dust hopper against dirty gas flow and thus it has to have settling velocity. In another words, shape and size of fractures determine whether or not fractures drop down to the dust hopper or are recaptured by filter again.

Lu H.-C. and Tsai C.-J. (1998) studied to find the optimum design and operation parameters of a pulse-jet baghouse, and Ju J. et al. (2001) proposed a model to estimate the relation between filtration velocity and dust load in each cleaning cycle until reaching steady operation mode.

Improvement of collection performance of filter media is another important issue to improve the system performance. Fig. 26 is the comparison of filter collection efficiency by the difference of fiber mass and surface treatment. As seen from the figure, collection efficiency increases fiber mass from 400 to $700 \mathrm{~g} / \mathrm{m}^{2}$. However, collection efficiency of membrane laminated filter shows very high efficiency at any particle size despite that fiber mass of the basement filter is only $400 \mathrm{~g} / \mathrm{m}^{2}$.

\subsection{Particle collection by cartridge filter}

Cartridge filter was first developed as an air intake filter for vehicle engine and has been now used popularly even at high particle concentration region. Because of pleated and compact structure, filtration area per system volume can be larger than an ordinary cylindrical filter media and thus filter system size becomes small. However, cartridge filter has many problems relating to its structure.

Chen D.R. et al. (1995) and Chen D.R. and Pui D.Y.H. (1996) tried to optimize pleated filter designs by using a finite-element numerical model. Wakeman R.J. et al. (2005) analyzed the effects of medium compression, pleat deformation and pleat crowding are analyzed. Ming L. et al. (2010) experimentally studied 6 pleated fabric cartridges with different base media and geometrical dimensions in a pulse-jet cleaned dust collector. Then they evaluated the effect of cleaning methods and concluded that clean-on-demand mode performed better for filters with a low pleat ratio $(<4.0)$. Lo L. et al. $(2010 a, b)$ numerically and experimentally studied pleated fabric cartridges during pulse-jet cleaning. Joubert A. et al. (2010) evaluated the influence of humidity on the clogging pleated HEPA filters. Park B.H. et al. (2012) studied the influence of pleat geometry on filter cleaning in PTFE/ glass composite filter. Bemer D. et al. (2013) studied clogging and cleaning cycles of a pleated cartridge filter by ultrafine particles. Hasolli N. et al. (2013a, b) evaluated the filtration performance of depth filter media cartridges as function of layer structure and pleat count. Bourrous S. et al. (2014) measured the nano-particles distribution in the pleated filters during clogging. Li J. et al. (2015) studied the improvement of dust cleaning effect by the installation of cone in a pleated filter cartridge during pulse-jet cleaning. Feng Z. and Long Z. (2016) simulated unsteady filtration. Kim J.-U. et al. (2017) evaluated the effective filtration area of a pleated filter bag in a pulse-jet bag house and found that effective filtration area decreases considerably due to its geometric configuration and dust clogging between pleat. Chen S. et al. (2017) studied the effect of pleat shape on reverse pulsed-jet cleaning of filter cartridges by CDF analysis and concluded that the shape of pleats has its effect on the pressure drop across pleated cartridges and pleat tip opening improves the uniformity of pressure on inner surfaces of pleats. Finally, they concluded trapezoidal pleat shape is a better candidate for pleating filter cartridges.

\section{Summary}

In this article, researches relating to dust collector using fiber as particle collection body, i.e., air filter, cartridge filter and nonwoven bag filter, were reviewed.

Particle collection process of air filter can be classified into 3 stages, i.e., Stage 1 (inner filtration I: collection by a fresh fiber), Stage 2 (inner filtration II: collection by both fresh and dust loaded fiber) and Stage 3 (surface filtration: collection by dust cake on the filter surface).

Particle collection in Stage 1 is practically applicable as far as collection efficiency and pressure drop of filter are stable. Collection behaviour of this stage is well understood and established for circular cylinder except in single nano-particles. However, effects of filter structure, inhomogeneity in fiber size and shape, and non-uniformity of fiber packing are not well understood.

Particle collection by fresh and dust loaded fiber take place in Stage 2. Due to the stochastic nature of particle collection, analysing method has not been established but analysing techniques using CDF are progressing. However, there are many parameters and issue remained in this stage. Especially, to find the suitable filter structure having large dust holding capacity is the important issue in this stage.

Particle collection Stage 3 is practically very important but due to the complicated phenomena, it is not well understood. Hence, most of dust collectors are designed on empirical basis. Hence, fundamental study in this stage is still needed. 


\section{Nomenclature}

A constant defined by Eqn. (27) $[1 / \mathrm{m}]$

$b \quad$ empirical coefficient in Eqn. (29) $\left[\left(\mathrm{kg} / \mathrm{m}^{3}\right)^{-c}\right]$

$C \quad$ particle concentration $\left[\mathrm{kg} / \mathrm{m}^{3}\right]$

$C_{\mathrm{C}} \quad$ Cunningham correction factor $[-]$

$C_{\mathrm{D}} \quad$ Drag coefficient of a fiber [-]

$c \quad$ empirical exponent in Eqn. (29) [-]

$\Delta D$ displacement of dust cake from filter surface

$D_{\text {BM }}$ diffusion constant $\left[\mathrm{m}^{2} / \mathrm{s}\right]$

$\Delta D_{\mathrm{d}}$ displacement of surface of dust cake measured from dirty side $[\mathrm{m}]$

$\Delta D_{\mathrm{f}}$ displacement of filter surface measured from clean side [m]

d size $[\mathrm{m}]$

$E \quad$ filter efficiency [-]

$G \quad$ Gravitational parameter $\left(=\rho_{\mathrm{p}} d_{\mathrm{p}}{ }^{2} g / 18 \mu u\right)[-]$

$g \quad$ acceleration of gravity $\left(\mathrm{m} / \mathrm{s}^{2}\right)$

$H \quad$ distance between neighboring fibers

$h \quad$ hydrodynamic factor $[-]$

$k \quad$ constant in Eqn. (30)

$L \quad$ filter thickness [m]

$m \quad$ dust load per unit filter volume $\left[\mathrm{kg} / \mathrm{m}^{3}\right]$

$R \quad$ Interception parameter $\left(=d_{\mathrm{p}} / d_{\mathrm{f}}\right)[-]$

Re Reynolds number $\left(=\rho_{\mathrm{g}} d_{\mathrm{f}} u / \mu\right)[-]$

$P \quad$ penetration $[-]$

pe number of elementary charges in particle [-]

$P e \quad$ Peclet number $\left(=d_{\mathrm{f}} u / D_{\mathrm{BM}}\right)[-]$

$S \quad$ filtration area $\left[\mathrm{m}^{2}\right]$

Sc $\quad$ Schmidt number $\left(=\mu /\left(\rho_{\mathrm{g}} D_{\mathrm{BM}}\right)[-]\right.$

Stk Stokes number $\left(=C_{\mathrm{c}} \rho_{\mathrm{p}} d_{\mathrm{p}}{ }^{2} u / 9 \mu d_{\mathrm{f}}\right)[-]$

$T$ temperature [K]

$u \quad$ particle velocity or filtration velocity $[\mathrm{m} / \mathrm{s}]$

$u_{\mathrm{a}} \quad$ approaching velocity to a fiber $[\mathrm{m} / \mathrm{s}]$

$x \quad$ distance from filter inlet $[\mathrm{m}]$

$z_{\mathrm{p}} \quad$ electrical mobility $\left[\mathrm{m}^{2} /(\mathrm{V} \cdot \mathrm{s})\right]$

$\alpha \quad$ packing density [-]

$\beta(x)$ deposition distribution function given in Eqn. (30) [-]

$\varepsilon \quad$ porosity of filter $[-]$

$\eta \quad$ single fiber collection efficiency $[-]$

$\kappa \quad$ Boltzmann constant $\left(=1.38064852 \times 10^{-23}\right)[\mathrm{J} / \mathrm{K}]$

$\lambda \quad$ collection raising factor $[-]$ $\begin{array}{ll}\mu & \text { gas viscosity }[\mathrm{Pa} \cdot \mathrm{s}] \\ \rho & \text { density }\left[\mathrm{kg} / \mathrm{m}^{3}\right]\end{array}$

Subscript

av average

D diffusion

f fiber

g gas

G gravity

I inertia

K Kuwabara

L Lamb

m dust loaded

p particle

$\mathrm{R} \quad$ interception

$0 \quad$ without dust load

\section{References}

Agranovski I.E., Shapiro M., Clogging of wet filters by dust particles, Journal of Aerosol Science, 32 (2001) 1009-1020.

Alonso M., Kousaka Y., Hashimoto T., Hashimoto N., Penetration of nanometer-sized aerosol particles through wire screen and laminar flow tube, Aerosol Science and Technology, 27 (1997) 471-480.

Ardkapan S.R., Johnson M.S., Yazdi S., Afshari A., Bergsøe N.C., Filtration efficiency of an electrostatic fibrous filter: Studying filtration dependency on ultrafine particle exposure and composition, Journal of Aerosol Science, 72 (2014) $14-20$.

Bahners T., Schollmeyer E., Computer simulation of the filtration process in a fibrous filter collecting polydisperse dust, Journal of Aerosol Science, 17 (1986) 191-197, 199-200.

Bao L., Otani Y., Namiki N., Mori J., Emi H., Prediction of HEPA filter collection efficiency with a bimodal fiber size distribution, Kagaku Kogaku Ronbunshu, 24 (1998) 766771.

Bao L., Kobayashi M., Aomi H., Matsuzaki H., Kiyotani H., Shibuya Y., Chaen S., Inui K., Kuo C.C., Siang D.K., Bin Z., Wei N.C., Balgis R., Ogi T., Okuyama K., Otani Y., Lin Z., Performance evaluation of the HEPA filter made of depth filtration nano-fiber media, 33rd Annual Tech. Meeting on Air Cleaning and Contamination Control proceeding, JACA (Japan Air Cleaning Association), 2015, pp. 90-93.

Baumgartner H.-P., Löffler F., The collection performance of electret filters in the particle size range $10 \mathrm{~nm}-10 \mu \mathrm{m}$, Journal of Aerosol Science, 17 (1986) 438-445.

Baumgartner H., Löffler F., Three-dimensional numerical simulation of the deposition of polydisperse aerosol particles on filter fibres-extended concept and preliminary results, 

drop of a filter media with loading, Aerosol Science and Technology, 33 (2000) 427-439.

Bemer D., Regnier R., Morele Y., Grippari F., Appert-collin J.C., Thoms D., Study of clogging and cleaning cycles of a pleated cartridge filter used in a thermal spraying process to filter ultrafine particles, Powder Technology, 234 (2013) $1-6$.

Bhutra S., Payatakes A.C., Experimental investigation of dendritic deposition of aerosol particles, Journal of Aerosol Science, 10 (1979) 445-464.

Billings C.E., Effects of particle accumulation in aerosol filtration, W. M. Keck Laboratory of Environmental Health Engineering Report, California Institute of Technology, Pasadena, 1966.

Billings C.E., Wilder J., Handbook of fabric filter technology, Vol. 1: fabric filter systems study, GCA-TR-70-17-G, GCA Corporation, 1970.

Binnig J., Bredin A., Meyer J., Kasper G., Dimensional analysis of the cleaning pulse intensity in a surface filter test rig, Powder Technology, 211 (2011) 275-279.

Boskovic L., Altman I.S., Agranovski I.E., Braddock R.D., Myojo T., Choi M., Influence of particle shape on filtration processes. Aerosol Science and Technology, 39 (2005) 1184-1190.

Boskovic L. Agranovski I.E., Braddock R.D., Filtration of nanosized particles with different shape on oil coated fibres, Journal of Aerosol Science, 38 (2007) 1220-1229.

Boskovic L., Agranovski I.E., Altman I.S., Braddock, R.D., Filter efficiency as a function of nanoparticle velocity and shape, Journal of Aerosol Science, 39 (2008) 635-644.

Bourrous S., Bouilloux L., Ouf F.X., Appert-Collin J.C., Thomas D., Tampère L., Morele Y., Measurement of the nanoparticles distribution in flat and pleated filters during clogging, Aerosol Science and Technology, 48 (2014) 392400.

Bourrous S., Bouilloux L., Ouf F.-X., Lemaitre P., Nerisson P., Thomas D., A.-Collin J.C., Measurement and modeling of pressure drop of HEPA filters clogged with ultrafine particles, Powder Technology, 289 (2016) 109-117.

Brown R.C., A many-fibre theory of airflow through a fibrous filter, Journal of Aerosol Science, 15 (1984) 583-593.

Brown R.C., A many-fibre theory of airflow through a fibrous filter-II: fluid inertia and fibre proximity, Journal of Aerosol Science, 17 (1986) 685-697.

Brown R.C., Davies J.K.W., Wake D., Penetration of test aerosols through filters described in terms of a gamma distribution of layer efficiencies, Journal of Aerosol Science, 18 (1987) 499-509.

Brown R.C., Wake D., Gray R., Blackford D.B., Bostock G.J., Effect of industrial aerosols on the performance of electrically charged filter material, The Annals of Occupational Hygiene, 32 (1988) 271-294.

Brown R.C., Wake D., Air filtration by interception-theory and experiment, Journal of Aerosol Science, 22 (1991) 181-186.

Brown R.C., Air Filtration, Pergamon Press, Oxford, 1993.

Brown R.C., Thorpe A., Glass-fibre filters with bimodal fibre

size distributions, Powder Technology, 118 (2001) 3-9.

Cai J., Peterson F., Efficiency for monodisperse particles in instationary filtration, Journal of Aerosol Science, 20 (1989a) 955-958.

Cai J., Some remarks on efficiency due to dendrite formation, Journal of Aerosol Science, 20 (1989b) 959-962.

Chen D.R., Pui D.Y.H., Liu B.Y.H., Optimization of pleated filter designs using a finite-element numerical model, Aerosol Science and Technology, 23 (1995) 579-590.

Chen D.R., Pui D.Y.H., Optimization of pleated filter designs, Journal of Aerosol Science, 27 (1996) 654-655.

Chen S., Wang Q., Chen D.-R., Effect of pleat shape on reverse pulsed-jet cleaning of filter cartridges, Powder Technology, 305 (2017) 1-11.

Cheng Y.-H., Tsai C.-J., Factors influencing pressure drop through a dust cake during filtration, Aerosol Science and Technology, 29 (1998) 315-328.

Chazelet S., Bemer D., Grippari F., Effect of the test aerosol charge on the penetration through electret filter, Separation and Purification Technology, 79 (2011) 352-356.

Choi H.-J., Kim S.-B., Kim S. H., Lee M.-H., Preparation of electrospun polyurethane filter media and their collection mechanisms for ultrafine particles, Journal of the Air \& Waste Management Association, 64 (2014) 322-329.

Choi H.-J., Park E.-S., Kim J.-U., Kim S.H., Lee M.-H., Experimental study on charge decay of electret filter due to organic solvent exposure, Aerosol Science and Technology, 49 (2015) 977-983.

Contal P., Simao J., Thomas D., Frising T., Callé S., AppertCollin, J.C., Bémer D., Clogging of fibre filters by submicron droplets, Phenomena and influence of operating conditions, Journal of Aerosol Science, 35 (2004) 263-278.

Dahneke B., The capture of aerosol particles by surfaces, Journal of Colloid and Interface Science, 37 (1971) 342-353.

Davies C.N., The Separation of airborne dust and particles, Proceedings of the Institution of Mechanical Engineers, Part B: Management and engineering manufacture, 1 (1953) 185213.

Davies C.N., Peetz C.V., Impingement of particles on a transverse cylinder, Proceedings of the Royal Society of London Series A, Mathematical and Physical Sciences, 234 (1956) 269-295.

Davies C.N., Aerosol Science, Academic Press, New York, 1966.

Davies C.N., The clogging of fibrous aerosol filters, Journal of Aerosol Science, 1 (1970) 35-39.

Dennis R., Klemm H.A., Fabric filter model format change. Vol. I. detailed technical report, Vol. II. user's guide, U.S. Environmental Protection Agency, Industrial Environmental Research Laboratory, Research Triangle Park, NC, EPA600/7-79-043a, EPA-600/7-79-043b, 1979a.

Dennis R., Klemm H.A., A model for coal fly ash filtration, JAPCA (Journal of the Air Pollution Control Association), 29 (1979b) 230-234.

Dennis R., Klemm H.A., Modeling concepts for pulse jet filtration, JAPCA (Journal of the Air Pollution Control Association), 30 (1980) 38-43.

Dennis R., Wilder J.E., Harmon D.L., Predicting pressure loss 
de forkpulse jet filters, Journal of the Air Pollution Control WAssociation, 31 (1981) 987-992.

Dhaniyala S., Liu B.Y.H., Investigations of particle penetration in fibrous filters: Part I. Experimental, Journal of the IEST, 42 (1999a) 32-40.

Dhaniyala S., Liu B.Y.H., Investigations of particle penetration in fibrous filters: Part II. theoretical, Journal of the IEST, 42 (1999b) 40-46.

Dhaniyala S., Liu B.Y.H., Theoretical modeling of filtration by nonuniform fibrous filters, Aerosol Science and Technology, 34 (2001)170-178.

Donovan R.P., Fabric filtration for combustion sources: fundamentals and basic technology, Marcel Dekker, 1985.

Dunnett S.J., Clement C.F., A numerical study of the effects of loading from diffusive deposition on the efficiency of fibrous filters, Journal of Aerosol Science, 37 (2006) 11161139.

Dunnett S.J., Clement, C.F., Numerical investigation into the loading behaviour of filters operating in the diffusional and interception deposition regimes, Journal of Aerosol Science, 53 (2012) 85-99.

Ellenbecker M.J., Leith D., The effect of dust retention on pressure drop in a high velocity pulse-jet fabric filter, Powder Technology, 25 (1980) 147-154.

Ellenbecker M.J., Leith D., Dust removal characteristics of fabrics used in pulse-jet filters, Powder Technology, 36 (1983) $13-19$.

El-shobokshy M.S., Al-Sanea S.A., Adnan A.M., Computer simulation of monodisperse aerosol collection in fibrous filters, Aerosol Science and Technology, 20 (1994) 149-160.

Emi H., Okuyama K., Yoshioka N., Prediction of collection efficiency of aerosols by high-porosity fibrous filter, Journal of Chemical Engineering of Japan, 6 (1973) 349-354.

Emi H., Okuyama K., Adachi M., The effect of neighbouring fibers on the single fiber inertia-interception efficiency of aerosols, Journal of Chemical Engineering of Japan, 10 (1977) 148-153.

Emi H., Kanaoka C., Collection efficiency of high efficiency particulate air filter, Proceeding of International Symposium on Powder Technology '81, 1981, pp. 517-524.

Emi H., Kanaoka C., Kuwabara Y., The diffusion collection efficiency of fibers for aerosol over a wide range of Reynolds numbers, Journal of Aerosol Science, 13 (1982a) 403413.

Emi H., Kanaoka C., Ishiguro T., Collection performance of high efficiency air filters, $6^{\text {th }}$ Int. Sympo. Cont. Control, Tokyo, (1982b) 219-222.

Emi H., Kanaoka C., Otani Y., Ishiguro T., Collection mechanisms of electret filter, Particulate Science and Technology, 5 (1987) 161-171.

Endo Y., Chen D.-R., Pui D.Y.H., Air and water permeation resistance across dust cakes on filters-effects of particle polydispersity and shape factor, Powder Technology, 118 (2001) 24-31.

Eryu K., Seto T. Furuuchi M., Otani Y., Tajima N., Kato T., Effects of filter packing density and particle deposit on classification performance of inertial filter for sampling of $\mathrm{PM}_{0.1}$, Journal of Chemical Engineering of Japan, 44 (2011)
609-615.

Fang C., Xu J., Zhao H., Li W., Liu H., Experimental investigation on particle entrainment behaviors near a nozzle in gasparticle coaxial jets, Powder Technology, 286 (2015) 55-63.

Feng Z., Long Z., Modeling unsteady filtration performance of pleated filter, Aerosol Science and Technology, 50 (2016) 626-637.

Fotovati S., Vahedi Tafreshi H., Pourdeyhimi B., Influence of fiber orientation distribution on performance of aerosol filtration media, Chemical Engineering Science, 65 (2010) 5285-5293.

Friedlander S.K., Mass and heat transfer to single spheres and cylinders at low Reynolds numbers. AIChE Journal, 3 (1957) 43-48.

Friedlander S.K., Theory of aerosol filtration, Industrial \& Engineering Chemistry, 50 (1958) 1161-1164.

Friedlander S.K., Smoke, dust and haze: Fundamentals of aerosol behavior, New York: Wiley, 1977.

Friedlander S.K., Smoke, Dust, and Haze: Fundamentals of Aerosol Dynamics, Oxford University Press, New York, 2000.

Fuchs N.A., Stechkina I.B., A note on the theory of fibrous aerosol filters, The Annals of Occupational Hygiene, 6 (1963) 27-30.

Fuchs N.A., The mechanics of aerosols, ed. by C.N. Davies, Oxford : Pergamon Press, 1964.

Givehchi R., Tan Z., An overview of airborne nano-particle filtration and thermal rebound theory, Aerosol and Air Quality Research, 14 (2014) 45-63.

Givehchi R., Tan Z., The effect of capillary force on airborne nanoparticle filtration, Journal of Aerosol Science, 83 (2015) 12-24.

Golanski L., Guiot A., Rouillon F., Pocachard J., Tardif F., Experimental evaluation of personal protection devices against graphite nanoaerosols: fibrous filter media, masks, protective clothing, and gloves, Human \& Experimental Toxicology, 28 (2009) 353-359.

Gopal R., Kaur S., Ma Z., Chan C., Ramakrishna S., Matsuura T., Electrospun nanofibrous filtration membrane, Journal of Membrane Science, 281 (2006) 581-586.

Gupta A., Novick V.J., Biswas P., Monson P.R., Effect of humidity and particle hygroscopicity on the mass loading capacity of high efficiency particulate air (HEPA) Filters, Aerosol Science and Technology, 19 (1993) 94-107.

Hakamata T., Ushiroebisu K., Suzuki K., Yoneda T., Performance of pulse jet bag filter, $6^{\text {th }}$ World Filtration Congress, (1993) 483-486.

Happel J., Viscous flow relative to arrays of cylinders, AIChE Journal, 5 (1959) 174-177.

Hasolli N., Park Y.O., Rhee Y.W., Filtration performance evaluation of depth filter media cartridges as function of layer structure and pleat count, Powder Technology, 237 (2013a) 24-31.

Hasolli N., Park Y.O., Rhee Y.W., Experimental study on filtration performance of flat sheet multiple-layer depth filter media for intake air filtration, Aerosol Science and Technology, 47 (2013b) 1334-1341.

Heim M., Mullins B.J., Wild M., Meyer J., Kasper G., Filtration 


\section{and or}

efficiency of aerosol particles below 20 nanometers, AeroW'Sol Science and Technology, 39 (2005) 782-789.

Heim M., Attoui M., Kasper G., The Efficiency of diffusional particle collection onto wire grids in the mobility equivalent size range of 1.2-8 nm, Journal of Aerosol Science, 41 (2010) 207-222.

Hinds W.C., Kadrichu N.P., The effect of dust loading on penetration and resistance of glass fiber filters, Aerosol Science and Technology, 27 (1997) 162-173.

Hinds W.C., Aerosol Technology: Properties, Behavior, and Measurement of Airborne Particles, 2nd Edition, John Wiley and Sons Inc., 1999, ISBN: 978-0-471-19410-1.

Hiragi S., Performance of dust loaded fibrous air filter, Ph.D. thesis, Kanazawa University, 1990a.

Hiragi S., Kanaoka C., Yamada K., Morphology of particle agglomerate on a fiber in air filter, Kagaku Kogaku Ronbunshu, 16 (1990b) 252-258.

Hirota M., Fudoh A., Mizuno Y., Oshima T., Effect of the flowability of dust on characteristics of dust collection by a filter cloth, Kagaku Kogaku Ronbunshu, 11 (1985) 7-12.

Hirota M., Shimizu Y., Oshima T., Effect of the flowability of dust on collection performance of repeatedly dislodged filter cloth, Kagaku Kogaku Ronbunshu, 13 (1987) 113-116.

Huang B., Yao Q., Li S.-Q., Zhao H.-L., Song Q., You C.-F., Experimental investigation on the particle capture by a single fiber using microscopic image technique, Powder Technology, 163 (2006) 125-133. DOI: https://doi.org/10.1016/ j.powtec.2006.01.014

Huang S., Chen C., Chang C., Lai C., Chen C., Penetration of $4.5 \mathrm{~nm}$ to $10 \mu \mathrm{m}$ aerosol particles through fibrous filters, Journal of Aerosol Science, 38 (2007) 719-727.

Hunag S.-H., Kuo Y.-M., Chang K.-N., Chen Y.-K.-Y., Lin W., Lin W.-Y., Chen C.-C., Experimental study on the effect of fiber orientation on filter quality, Aerosol Science and Technology, 44 (2010) 964-971.

Hubbard J.A., Brockmann J.E., Dellinger J., Lucero D.A., Sanchez A.L., Servantes B.L., Fibrous filter efficiency and pressure drop in the viscous-inertial transition flow regime, Aerosol Science and Technology, 46 (2012) 138-147. DOI: 10.1080/02786826.2011.616555

Humphries W., Influence of cloth structure on dust dislodgement from fabric filters, Powder Technology, 28 (1981) 189-194.

Hunt B., Thajudeen T., Hogan C.J., The single-fiber collision rate and filtration efficiency for nanoparticles $\mathrm{I}$ : The first-passage time calculation approach, Aerosol Science and Technology, 48 (2014) 875-885.

Ichitsubo H., Hashimoto T., Alonso M., Kousaka Y., Penetration of ultrafine particles and ion clusters through wire screens, Aerosol Science and Technology, 24 (1996) 119-127.

Iinoya K., Makino K, Kimura N., Experiments of dust collection by an electric charged fibrous filter, Chemical Engineering, 29 (1965) 574-578.

Iinoya K. Makino K., Inoue O., Imamura T., Dust collection performance of paper filters, Chemical Engineering, 34 (1970) 632-637.

Iinoya K., Mori Y., Makino K., Komatsu N., Ozaki M., Nagashima R., Dust dislodging performance of a pulse-jet fabric filter, Kagaku Kogaku Ronbunshu, 5 (1979) 500-505.

Ikazaki F., Toyama S., Makino K., Tada Y., Iinoya K., Mechanism of electrical dislodging of dust layer, Kagaku Kogaku Ronbunshu, 4 (1978) 117-122.

Ikeno H., Tada Y., Hiraoka S., Ikei M., Shuto Y., Study of pressure drop in bag filter based on patched cleaning model, Kagaku Kogaku Ronbunshu, 30 (2004) 14-21.

Ikeno H., Tada Y., Ishino T., Watanabe K., Effects of pressure drop and filter medium on the collection performance of bag filter, Journal of the Society of Powder Technology, Japan, 46 (2009) 598-604.

Inagaki M., Sakai K., Namiki N., Emi H., Otani Y., Effect of shape of fiber cross section on filter performance, Kagaku Kogaku Ronbunshu, 27 (2001) 113-120.

Ingham D.B., The diffusional deposition of aerosols in fibrous filters, Journal of Aerosol Science, 12 (1981) 357-365.

Janssen L.L., Bidwell J.O., Mullins H.E., Nelson T.J., Efficiency of degraded electret filters: part I-laboratory testing against $\mathrm{NaCl}$ and DOP before and after exposure to workplace Aerosols, Journal of the International Society for Respiratory Protection, 20 (2003) 71-80.

Japuntich D.A., Stenhouse J.I.T., Liu B.Y.H., Experimental results of solid monodisperse particle clogging of fibrous filters, Journal of Aerosol Science, 25 (1994) 385-393.

Japuntich D.A., Franklin L.M., Pui D.Y., Kuehn T.H., Kim S.C., Viner A.S., A comparison of two nano-sized particle air filtration tests in the diameter range of 10 to 400 nanometers, Journal of Nanoparticle Research, 9 (2007) 93-107.

Ji J.H., Bae G.N., Kang S.H., Hwang J., Effect of particle loading on the collection performance of an electret cabin air filter for submicron aerosols, Journal of Aerosol Science, 34 (2003) 1493-1504

Jin X., Yang L., Du X., Yang Y., Modeling filtration performance of elliptical fibers with random distributions, Advanced Powder Technology, 28 (2017) 1193-1201.

Joubert A., Laborde J.C., Bouilloux L., Chazelet S., Thomas D., Influence of humidity on clogging of flat and pleated HEPA filters, Aerosol Science and Technology, 44 (2010) 10651076 .

Joubert A., Laborde J.C., Bouilloux L., Chazelet S., Thomas D., Modelling the pressure drop across HEPA filters during cake filtration in the presence of humidity, Chemical Engineering Journal, 166 (2011) 616-623.

Ju J., Chiu M.-S., Tien C., Further work on pulse-jet fabric filtration modeling, Powder Technology, 118 (2001) 79-89.

Kanaoka C., Emi H., Myojo T., Simulation of deposition and growth of airbone particles on a fiber, Kagaku Kogaku Ronbunshu, 4 (1978) 535-537.

Kanaoka C., Emi H., Myojo T., Ohta M., Estimation of collection efficiency of an air filter with dust load, I.CHEM. E. Smpo. Series. No.59, (1980a) pp. 3:4/1-3:6/15.

Kanaoka C., Emi H., Myojo T., Simulation of the growing process of a particle dendrite and evaluation of a single fiber collection efficiency with dust load, Journal of Aerosol Science, 11 (1980b) 377-389.

Kanaoka C., Emi H., Ohta M., Performance of loaded air filters, $3^{\text {rd }}$ Smpo. The transfer and utilization of particulate control technology, vol.III, EPA-600/9-82-005c, (1982) 280-289. 
Kanaok C., Emi H., Tanthapanichakoon W., Convective diffuWSional deposition and collection efficiency of aerosol on a dust-loaded fiber, AIChE Journal, 29 (1983) 895-902.

Kanaoka C., Emi H., Deguchi A., Effect of inter-fiber distance on collection efficiency of a single fiber in a model filter composed of parallel fibers in a row, in: Aerosols ed. by B.Y.H. Liu et al.(Elsevier), (1984a) pp. 536-536.

Kanaoka C., Emi H., Ishiguro T., Time dependency of collection performance of electret filter, in: Aerosols ed. by Liu et al.(Elsevier), 1984b pp. 613-616.

Kanaoka C., Emi H., Hiragi S., Myojo T., Morphology of particulate agglomerates on a cylindrical fiber and a collection efficiency of a dust loaded fiber, Aerosols-Formation and Reactivity, Pergamon Press, 1986, pp. 674-677.

Kanaoka C., Emi H., Otani Y., Iiyama T., Effect of charging state of particles on electret filtration. Aerosol Science and Technology, 7 (1987) 1-13.

Kanaoka C., Dust collection 2, Journal of the Society of Powder Technology, Japan, 25 (1988) 469-479.

Kanaoka C., Hiragi, S., Pressure drop of air filter with dust load, Journal of Aerosol Science, 21 (1990) 127-131.

Kanaoka C., Furuuchi M., Murai J., The dust cleaning mechanism of a pulse jet type bag filter, Journal of the Society of Powder Technology, Japan, 31 (1994) 424-429.

Kanaoka C., Hiragi S., Tanthapanichakoon T., Stochastic simulation of the agglomerative deposition process of aerosol particles on an electret fiber, Powder Technology, 118 (2001) 97-106.

Kanaoka C., Yao Y.P., Time dependency of the pressure drop in a flat type pulse jet fabric filter, Kagaku Kogaku Ronbunshu, 29 (2003) 267-271.

Kanaoka C., Bao L., Kobayashi M., Packing density distribution of fiber in a nonwoven filter media, 33rd Annual Tech. Meeting on Air Cleaning and Contamination Control proceeding, JACA (Japan Air Cleaning Association), 2016, pp. 96-99.

Kanaoka C., Bao L., Kobayashi M., Kimura I., Effect of surface structure on filter performance, 34th JACA (Japan Air Cleaning Association), 2017, pp. 121-124.

Kao T.-H., Su S.-K., Su C.-I., Lee A.-W., Chen J.-K., Polyacrylonitrile microscaffolds assembled from mesh structures of aligned electrospun nanofibers as high-efficiency particulate air filters, Aerosol Science and Technology, 50 (2016) 615-625.

Karadimos A., Ocone R.,' The effect of the flow field recalculation on fibrous filter loading: a numerical simulation, Powder Technology, 137 (2003) 109-119.

Kasper G., Schollmeter S., Meyer J., Hoferer J., The collection efficiency of a particle-loaded single filter fiber, Journal of Aerosol Science, 40 (2009) 993-1009.

Kasper G., Schollmeter S., Meyer J., Structure and density of deposits formed on filter fibers by inertial particle deposition and bounce, Journal of Aerosol Science, 41 (2010) 1167-1182.

Kawabe M., Iskandar F., Okuyama K., Corona charging process for polypropylene electret filter, Journal of the Institute of Electrostatics Japan, 33 (2009) 213-219.

Kilic A., Shim E.E., Pourdeyhimi B., Electrostatic capture effi- ciency enhancement of polypropylene electret filters with barium titanate, Aerosol Science and Technology, 49 (2015) $666-673$

Kim C.S., Bao L., Okuyama K., Shimada M., Niinuma, H., Filtration efficiency of a fibrous filter for nanoparticles, Journal of Nanoparticle Research, 8 (2006) 215-221.

Kim S.C., Harrington M.S., Pui D.Y.H., Experimental study of nanoparticles penetration through commercial filter media, Journal of Nanoparticle Research, 9 (2007) 117-125.

Kim J., Hinestroza J.P., Jasper W., Barker R.L., Effect of solvent exposure on the filtration performance of electrostatically charged polypropylene filter media, Textile Research Journal, 79 (2009) 343-350.

Kim J.-U., Hwang J., Choi H.-J., Lee M.-H., Effective filtration area of a pleated filter bag in a pulse-jet bag house, Powder Technology, 311 (2017) 522-527.

Kim S.C., Wang J., Shin W.G., Scheckman J.H., Pui D.Y.H., Structural properties and filter loading characteristics of soot agglomerates, Aerosol Science and Technology, 43 (2009) 1033-1041.

Kimura N., Iinoya K., Collection efficiency of single fiber mat filters, Chemical Engineering, 29 (1965) 538-546.

Kimura N., Iinoya K., Effect of fiber shape on performance of fiber mat filter, Chemical Engineering, 33 (1969a) 10081013.

Kimura N., Estimation for initial collection efficiency of a fibrous mat filters, Chemical Engineering, 33 (1969b) 1248-1254.

Kimura N., Iinoya K., Pressure drop of a fibrous mat filter with dust loading, Chemical Engineering, 33 (1969c) 1255-1260.

Kimura N., Shirato M., Collection efficiency of dry cloth-filter with dust loading, Chemical Engineering, 34 (1970) 984990.

Kimura N., Iwata M., Komatsu, K., Collection efficiency of fibrous mat filters with dust loads, Kagaku Kogaku Ronbunshu, 11 (1985) 621-627.

Kimura N., Kanamori M., Mori H., Shirato M., Dust load distributions in fibrous mat and granular bed filters, Kagaku Kogaku Ronbunshu, 15 (1989) 119-125.

Kirsch A.A., Fuchs N.A., Studies on fibrous aerosol filters-iii diffusional deposition of aerosols in fibrous filters, The Annals of Occupational Hygiene, 11 (1968) 299-304. DOI: 10.1093/annhyg/11.4.299

Kirsch A.A., The influence of an external electric field on the deposition of aerosols in fibrous filters, Journal of Aerosol Science, 3 (1972) 25-29.

Kirsch A.A., Stechkina I.B., Fuchs N.A., Effect of gas slip on the pressure drop in fibrous filters, Journal of Aerosol Science, 4 (1973) 287-293. DOI: https://doi.org/10.1016/ 0021-8502(73)90089-X

Kirsh A.A., Stechkina I.B., Fuchs N.A., Efficiency of aerosol filters made of ultrafine polydisperse fibres, Journal of Aerosol Science, 6 (1975) 119-120.

Kirsch A.A., Stechkina I.B., The theory of aerosol filtration with fibrous filters, Section 4, in: Fundamentals of Aerosol Science, D.T. Shaw (Ed.), Wiley-InterScience, New York, (1978) pp. 170-252.

Koch M., Krammer G., The Permeability distribution (PD) 
method for filter media characterization, Aerosol Science Wand Technology, 42 (2008) 433-444.

Kraemer H.F., Johnstone H.F., Collection of aerosol particles in presence of electrostatic fields, Industrial \& Engineering Chemistry, 47 (1955) 2426-2434. DOI: 10.1021/ie50552a020

Kuo Y.Y., Bruno F.C., Wang J., Filtration performance against nanoparticles by electrospun nylon-6 media containing ultrathin nanofibers, Aerosol Science and Technology, 48 (2014) 1332-1344.

Kuwabara S., The forces experienced by randomly distributed parallel circular cylinders or spheres in a viscous flow at small Reynolds numbers, Journal of the Physical Society of Japan, 14 (1959) 527-532. DOI: 10.1143/JPSJ.14.527

Lamb H., Hydrodynamics, Cambridge University Press, Cambridge, UK, 1932.

Landahl H.D., Herrmann R.G., Sampling of liquid aerosols by wires, cylinders, and slides, and the efficiency of impaction of the droplets, Journal of Colloid Science, 4 (1949) 103136. DOI: 10.1016/0095-8522(49)90038-0

Langumuir I., Filtration of aerosols and the development of filter materials, OSRD, Report No.865, 1942

Lee K.W., Liu B.Y.H., Experimental study of aerosol filtration by fibrous filters, Aerosol Science and Technology, 1 (1981) 35-46.

Lee K.W., Liu B.Y.H., Theoretical study of aerosol filtration by fibrous filters, Aerosol Science and Technology, 1 (1982) 147-161. DOI: 10.1080/02786828208958584

Lee M., Otani Y., Namiki N., Emi H., Prediction of collection efficiency of high-performance electret filters, Journal of Chemical Engineering of Japan, 35 (2002) 57-62. DOI: 10.1252/jcej.35.57

Leith D., First M.W., Performance of a pulse-jet filter at high filtration velocity I. Particle collection, Journal of the Air Pollution Control Association, 27 (1977a) 534-539. DOI: 10.1080/00022470.1977.10470452

Leith D., First M.W., Feldman H., Performance of a pulse-jet filter at high filtration velocity II. Filter cake redeposition, Journal of the Air Pollution Control Association, 27 (1977b) 636-642. DOI: 10.1080/00022470.1977.10470465

Leith D., First M.W., Gibson D.D., Performance of a high velocity pulse-jet filter, U.S. Environmental Protection Agency, Washington, D.C., EPA/600/7-78/131, 1978.

Leith D., Ellenbecker M.J., Theory for pressure drop in a pulsejet cleaned fabric filter, Atmospheric Environment (1967), 14 (1980) 845-852. DOI: 10.1016/0004-6981(80)90141-9

Leith D., Ellenbecker M.J., Dust emission characteristics of pulse-jet-cleaned fabric filters, Aerosol Science and Technology, 1 (1982) 401-408. DOI: 10.1080/02786828208958604

Leung W.W.-F., Hung C.-H., Investigation on pressure drop evolution of fibrous filter operating in aerodynamic slip regime under continuous loading of sub-micron aerosols, Separation and Purification Technology, 63 (2008) 691-700. DOI: 10.1016/j.seppur.2008.07.015

Leung W.W.-F., Hung C.-H., Yuen P.-T., Experimental investigation on continuous filtration of sub-micron aerosol by filter composed of dual-layers including a nanofiber layer, Aerosol Science and Technology, 43 (2009) 1174-1183.

Li J., Li S., Zhou F., Effect of cone installation in a pleated filter cartridge during pulse-jet cleaning, Powder Technology, 284 (2015) 245-252.

Li S.Q., Marshall J.S., Discrete element simulation of micro-particle deposition on a cylindrical fiber in an array, Journal of Aerosol Science, 38 (2007) 1031-1046.

Lo L., Hu S., Chen D.R., Pui D.Y.H., Numerical study of pleated fabric cartridges during pulse-jet cleaning, Powder Technology, 198 (2010a) 75-81.

Lo L., Chen D.R., Pui D.Y.H., Experimental study of pleated fabric cartridges in a pulse-jet cleaned dust collector, Powder Technology, 197 (2010b) 141-149.

Löffler F., Dietrich H., Flatt W., Dust Collection with Bag Filters and Envelope Filters, Springer, 1988, ISBN 978-3-66307900-2

Lu H.-C., Tsai C.-J., A Pilot-scale study of the design and operation parameters of a pulse-jet baghouse, Aerosol Science and Technology, 29 (1998) 510-524.

Lundgren D.A., Whitby K.T., Effect of particle electrostatic charge on filtration by fibrous filters, Industrial \& Engineering Chemistry Process Design and Development, 4 (1965) 345-349. DOI: 10.1021/i260016a001

Ma H., Yoon K., Rong L., Mao Y., Mo Z., Fang D., Hollander Z., Gaiteri J., Hsiao B.S., Chu B., High-flux thin-film nanofibrous composite ultrafiltration membranes containing cellulose barrier layer, Journal of Materials Chemistry, 20 (2010) 4692-4704. DOI: 10.1039/B922536F

Makino K., Iinoya K., Experiments on collection efficiency of dielectric fiber mat filter, Chemical Engineering, 32 (1968) 99-104. DOI: 10.1252/kakoronbunshu1953.32.99

Makino K., Iinoya K., Estimation of collection efficiency of a dielectric fibrous filter, Chemical Engineering, 33 (1969a) 684-689. DOI: 10.1252/kakoronbunshu1953.33.684

Makino K., Iinoya K., Collection efficiency of a single fiber in a fibrous filter and in a porous medium filter, Chemical Engineering, 33 (1969b) 1261-1265. DOI: 10.1252/kakoronbunshu1953.33.1261

Makino K., Iinoya K., Shibamoto M., Toyama S., Ikazaki F., Experiments on electrical dislodging of dust layer, Kagaku Kogaku Ronbunshu, 2 (1976) 31-37. DOI: 10.1252/ kakoronbunshu.2.31

Mao N., Yao Y., Hata M., Wada M., Kanaoka C., Comparison of filter cleaning performance between VDI and JIS testing rigs for cleanable fabric filter, Powder Technology, 180 (2008) 109-114.

Medjimorec V., Okuyama K., Payatakes A.C., Estimation of the drag forces acting on particle dendrites, Journal of Colloid and Interface Science, 82 (1981) 543-559. DOI: 10.1016/ 0021-9797(81)90396-9

Ming L., Chen D.R., Pui D.Y.H., Experimental study of pleated fabric cartridges in a pulse-jet cleaned dust collector, Powder Technology, 197 (2010) 141-149.

Mori Y., Kubori T., Ishizuka M., Makino K., Iinoya K., Fundamental experiments on the performance of dust filter fabrics, Kagaku Kougaku Ronbunshu, 5 (1979) 506-512.

Mouret G., Thomas D., Chazelet S., Collin J.-C.A., Bemer D., Penetration of nanoparticles through fibrous filters perforated with defined pinholes, Journal of Aerosol Science, 40 (2009) 762-775. 
bourete. Chazelet S., Thomas D., Bemer D., Discussion about

Wthe thermal rebound of nanoparticles, Separation and Purification Technology, 78 (2011) 125-131. DOI: 10.1016/j. seppur.2011.01.016

Mukhopadhyay, A., Pulse-jet filtration: An effective way to control industrial pollution Part I: Theory, selection and design of pulse-jet filter, Textile Progress, 41 (2009a) 195315.

Mukhopadhyay A., Pulse-jet filtration: An effective way to control industrial pollution Part II: Process characterization and evaluation of filter media, Textile Progress, 42 (2009b) $1-97$.

Müller T., Meyer J., Kasper G., Low Reynolds number drag and particle collision efficiency of a cylindrical fiber within a parallel array, Journal of Aerosol Science, 77 (2014a) 50-66. DOI: 10.1016/j.jaerosci.2014.07.007

Müller T.K., Meyer J., Thébault E., Kasper G., Impact of an oil coating on particle deposition and dust holding capacity of fibrous filters, Powder Technology, 253 (2014b) 247-255.

Myojo T., Kanaoka, C., Emi H., Experimental observation of collection efficiency of a dust-loaded fiber, Journal of Aerosol Science, 15 (1984) 483-489.

Naito M., Tsubaki J., Jimb G., Shearing direction dislodgement of deposited dust layer on fabric filter-dislodgement by impaction acceleration-, Kagaku Kougaku Ronbunshu, 10 (1984) 744-749.

Natanson G.L., Diffusional deposition of aerosols on a flowaround cylinder impact of electrostatic attraction, Doklady Akademii Nauk SSSR, 112 (1957a) 696-699.

Natanson G.L., Diffusional precipitation of aerosols on a streamlined cylinder with a small capture coefficient, Proceedings of the Academy of Sciences of the USSR, 112 (1957b) 21-25.

Nguyen X., Beeckmans J.M., Single fibre capture efficiencies of aerosol particles in real and model filters in the inertialinterceptive domain, Journal of Aerosol Science, 6 (1975) 205-212.

Nifuku M., Zhou Y., Kiaiel A., Kobayashi T., Katoh H., Charging characteristics for electret filter materials, Journal of Aerosol Science, 51-52 (2001) 200-2005.

Otani Y., Emi H., Mori J., Initial collection efficiency of electret filter and its durability for solid and liquid particles, Kagaku Kougaku Ronbunshu, 18 (1992) 240-247.

Otani Y., Emi H., Mori J., Initial collection efficiency of electret filter and its durability for solid and liquid particles, KONA Powder and Particle Journal, 11 (1993) 207-214.

Otani Y., Emi H., Cho S.J., Namiki N., Generation of nanometer size particles and their removal from air, Advanced Powder Technology, 6 (1995) 271-281.

Otani Y., Bao L., Namiki N., Hosokawa M., Emi H., Influence of internal structure of fibrous filter on collection performance at low Peclet number, Kagaku Kougaku Ronbunshu, 24 (1998) 772-777.

Overcamp T.J., Filtration by randomly distributed fibers, Journal of Aerosol Science, 16 (1985) 473-475.

Park B.H., Lee M.-H., Kim S.B., Kim G.S., Jo Y.M., Preparation and characterization of porous composite filter medium by polytetrafluoroethylene foam coating, Journal of the Air \&
Waste Management Association, 60 (2010) 137-141.

Park B.H., Lee M.-H., Jo Y.M., Kim S.B., Influence of pleat geometry on filter cleaning in PTFE/glass composite filter, Journal of the Air \& Waste Management Association, 62 (2012) 1257-1263

Payatakes A.C., Model of the dynamic behavior of a fibrous filter. Application to case of pure interception during period of unhindered growth, Powder Technology, 14 (1976a) 267278.

Payatakes A.C., Tien C., Particle deposition in fibrous media with dendrite-like pattern: A preliminary model, Journal of Aerosol Science, 7 (1976b) 85-94.

Payatakes A.C., Model of transient aerosol particle deposition in fibrous media with dendritic pattern, AIChE Journal, 23 (1977) 192-202.

Payatakes A.C., Gradoń L., Dendritic deposition of aerosol particles in fibrous media by inertial impaction and interception, Chemical Engineering Science, 35 (1980) 1083-1096. DOI: https://doi.org/10.1016/0009-2509(80)85097-4

Payatakes A.C., Okuyama K., Effects of aerosol particle deposition on the dynamic behavior of uniform or multilayer fibrous filters, Journal of Colloid and Interface Science, 88 (1982) 55-78. DOI: https://doi.org/10.1016/0021-9797(82) 90155-2

Payet S., Boulaud D., Madelaine G., Renoux A., Penetration and pressure drop of a HEPA filter during loading with submicron liquid particles. Journal of Aerosol Science, 23 (1992) 723-735

Pich J., Pressure drop of fibrous filters at small Knudsen numbers, The Annals of Occupational Hygiene, 9 (1966) 23-27. DOI: 10.1093/annhyg/9.1.23

Pich J., Emi H., Kanaoka C., Coulombic deposition mechanism in electret filters, Journal of Aerosol Science, 16 (1987) 29-35.

Pnueli D., Gutfinger C., Moldavsky L., Shuster K., Fichman M., Electrostatic porous filter with a blocking electrode, Journal of Aerosol Science, 31 (2000) 1371-1379.

Podgórski A., Bałazy A., Gradoń L., Application of nanofibers to improve the filtration efficiency of the most penetrating aerosol particles in fibrous filters, Chemical Engineering Science, 61 (2006) 6804-6815.

Podgórski A., Estimation of the upper limit of aerosol nanoparticles penetration through inhomogeneous fibrous filters, Journal of Nanoparticle Research, 11 (2009) 197-207. DOI: 10.1007/s11051-008-9472-2

Podgórski A., Maißer A., Szymanski W.W., Jackiewicz, A., Gradon, L., Singly charged nanoparticles through polydisperse fibrous filters, Journal of Aerosol Science and Technology, 45 (2011) 215-233.

Przekop R., Moskal A., Gradoń A., Lattice-Boltzmann approach for description of the structure of deposited particulate matter in fibrous filters, Journal of Aerosol Science, 34 (2003) 133-147.

Qian F., Huang N., Zhu X., Lu J., Numerical study of the gassolid flow characteristic of fibrous media based on SEM using CFD-DEM, Powder Technology, 249 (2013) 63-70.

Qian Y., Bi Y., Zhang M., Chen H., Xu G., Effect of filtration operation and surface treatment on pulse-jet cleaning per- 
e fortinance of filter bags, Powder Technology, 277 (2015) No2-88.

Rengasamy S., King W.P., Eimer B.C., Shaffer R.E., Filtration performance of NIOSH-approved N95 and P100 filtering facepiece respirators against 4 to 30 nanometer-size nanoparticles, Journal of Occupational and Environmental Hygiene, 5 (2008) 556-564. DOI: 10.1080/15459620802275387

Romay F.J., Liu B.Y.H., Chae S.-J., Experimental study of electrostatic capture mechanisms in commercial electret filters, Aerosol Science and Technology, 28 (1998) 224-234. DOI: 10.1080/02786829808965523

Sae-lim W., Tanthapanichakoon W., Kanaoka C., Correlation for the efficiency enhancement factor of a single electret fiber, Journal of Aerosol Science, 37 (2006) 228-240. DOI: 10.1016/j.jaerosci.2005.05.001

Sakano T., Otani Y., Namiki N., Emi H., Particle collection of medium performance air filters consisting of binary fibers under dust loaded conditions, Separation and Purification Technology, 19 (2000) 145-152. DOI: 10.1016/S1383-5866 (99)00086-6

Saleem M., Krammer G., Khan R.U., Tahir M.S., Influence of operating parameters on cake formation in pilot scale pulsejet bag filter, Powder Technology, 224 (2012) 28-35.

Sanchez A.L., Hubbard J.A., Dellinger J.G., Servantes B.L., Experimental study of electrostatic aerosol filtration at moderate filter face velocity, Aerosol Science and Technology, 47 (2013) 606-615.

Sato S., Chen D.R., Pui D.Y.H., Molecular dynamics study of nanoparticle collision with a surface-implication to nanoparticle filtration, Aerosol and Air Quality Research, 7 (2007) 278-303.

Scheibel H.G., Porstendörfer J., Penetration measurements for tube and screen-type diffusion batteries in the ultrafine particle size range, Journal of Aerosol Science, 15 (1984). 673-682.

Schmidt E., Löffler F., Preparation of dust cakes for microscopic examination, Powder Technology, 60 (1990) 173-177.

Schmidt E., Simulation of three-dimensional dust structures via particle trajectory calculations for cake-forming filtration, Powder Technology, 86 (1996) 113-117.

Shapiro, M., Kettner, I.J., Brenner, H., Transport mechanics and collection of submicrometer particles in fibrous filters. Journal of Aerosol Science, 22 (1991) 707-722.

Shin W.G., Mulholland G.W., Kim S.C., Pui D.Y.H., Experimental study of filtration efficiency of nanoparticles below $20 \mathrm{~nm}$ at elevated temperatures., Journal of Aerosol Science, 39 (2008) 488-499.

Shin-Kogaiboushi no gijutsutohouki 2015, Taiki-hen; Maruzen, 2015, p. 337, ISBN 978-4-86240-151-9.

Shou D., Fan J., Zhang H., Qian X., Ye L., Filtration efficiency of non-uniform fibrous filters, Aerosol Science and Technology, 49 (2015) 912-919.

Silva C.R.N., Negrini V.S., Aaguiar M.L., Coury J.R., Influence of gas velocity on cake formation and detachment, Power Technology, 101 (1999) 165-172.

Simon X., Chazelet S., Thomas D., Bémer D., Régnier R., Experimental study of pulse-jet cleaning of bag filters supported by rigid rings, Powder Technology, 172 (2007)
$67-81$.

Simon X., Bémer D., Chazelet S., Thomas D., Down-stream particle puffs emitted during pulse-jet cleaning of a baghouse wood dust collector: Influence of operating conditions and filter surface treatment, Powder Technology, 261 (2014) 61-70.

Skaptsov A.S., Baklanov A.M., Dubtsov S.N., Laulainen N.S., Sem G., Kaufman S., An experimental study of the thermal rebound effect of nanometer aerosol particles, Journal of Aerosol Science, 27 (1996) S145-S146.

Soltani P., Johari M.S., Zarrebini M., Effect of 3D fiber orientation on permeability of realistic fibrous porous networks, Powder Technology, 254 (2014) 44-56.

Song C.B., Park H.S., Lee K.W., Experimental study of filter clogging with monodisperse PSL particles, Powder Technology, 163 (2006) 152-159.

Stechkina I.B., Fuchs N.A., Studies on fibrous aerosol filters-I. Calculation of diffusional deposition of aerosols in fibrous filters, The Annals of Occupational Hygiene, 9 (1966) 59-64. DOI: 10.1093/annhyg/9.2.59

Stechkina I.B., Kirsch A.A., Fuchs N.A., Studies on fibrous aerosol filters-IV Calculation of aerosol deposition in model filters in the range of maximum penetration, The Annals of Occupational Hygiene, 12 (1969) 1-8. DOI: 10.1093/annhyg/12.1.1

Steffens J., Coury J.R., Collection efficiency of fiber filters operating on the removal of nano-sized aerosol particles: I-Homogeneous fibers, Separation and Purification Technology, 58 (2007a) 99-105. DOI: https://doi.org/10.1016/ j.seppur.2007.07.011

Steffens J., Coury J.R., Collection efficiency of fiber filters operating on the removal of nano-sized aerosol particles: II. Heterogeneous fibers, Separation and Purification Technology, 58 (2007) 106-112. DOI: https://doi.org/10.1016/j. seppur.2007.07.012

Stenhouse J.I.T., Japuntich D., Liu B.Y.H., The behaviour of fibrous filters in the initial stages of filter loading, Journal of Aerosol Science, 23 (1992) 761-764.

Smutek M., On the separation of air-borne particles by diffusion, Journal of Aerosol Science, 3 (1972) 337-343. DOI: https://doi.org/10.1016/0021-8502(72)90088-2

Takahashi T., Kanagawa A., Effect of an external electric field on the filtration of aerosols by fibrous filters, Kagaku Kogaku Ronbunshu, 1 (1975) 644-649.

Takahashi T., Kanagawa A., Collection of charged aerosol particles by fibrous filters, Kagaku Kogaku Ronbunshu, 4 (1978) 446-451.

Tanthapanichakoon W., Maneeintr K., Charinpanitkul T., Kanaoka C., Estimation of collection efficiency enhancement factor for an electret fiber with dust load, Journal of Aerosol Science, 34 (2003) 1505-1522.

Thomas J.W., Rimberg D., Miller T.J., Gravity effect in air filtration, Journal of Aerosol Science, 2 (1971) 31-38.

Thomas D., Ouf F.X., Gensdarmes F., Bourrous S., Bouilloux L., Pressure drop model for nanostructured deposits, Separation and Purification Technology, 138 (2014) 144-152. DOI: 10.1016/j.seppur.2014.09.032

Tsubaki J., Naito M., Tagami H., Kousaka H., Jimbo G., Dislog- 
al $v^{0}$

e dement of deposited dust layer on fabric filter by normal WStress dislodgement by impaction acceleration, Kagaku Kogaku Ronbunshu, 8 (1982) 481-486.

Turner J.H., Viner A.S., McKenna J.D., Jenkins R.E., Vatavuk W.M., Sizing and costing of fabric filters, JAPCA (Journal of the Air Pollution Control Association), 37 (1987a) 749759. DOI: $10.1080 / 08940630.1987 .10466261$

Turner J.H., Viner A.S., Jenkins R.E., Vatavuk W.M., McKenna J.D., Sizing and costing of fabric filters part II: Costing considerations, JAPCA (Journal of the Air Pollution Control Association), 37 (1987) 1105-1112. DOI: 10.1080/ 08940630.1987 .10466306

Turnhout J.V., Method for the manufacture of an electret fibrous filter, U.S Patent, (1976) No.3998916.

Van Osdell D.W., Liu B.Y.H., Rubow K.L., Pui D.Y.H., Experimental study of sub-micrometer and ultrafine particle penetration and pressure drop for high efficiency filters, Aerosol Science and Technology, 12 (1990) 911- 925.

van Gulijk C., Bal E., Schmidt-Ott A., Experimental evidence of reduced sticking of nanoparticles on a metal grid, Journal of Aerosol Science, 40 (2009) 362-369. DOI: https://doi. org/10.1016/j.jaerosci.2008.12.005

Wake D., Anomalous effects in filter penetration measurements using the aerodynamic particle sizer (APS 3300), Journal of Aerosol Science, 20 (1989) 13-17.

Wakeman R.J., Hanspal N.S., Waghode A.N., Nassehi V., Analysis of pleat crowding and medium compression in pleated cartridge filters, Chemical Engineering Research and Design, 83 (2005) 1246-1255. DOI: https://doi.org/10.1205/ cherd.04183

Walsh D.C., Stenhouse J.I.T., Scurrah K.L., Graef A., The effect of solid and liquid aerosol particle loading on fibrous filter material performance, Journal of Aerosol Science, 27 (1996) S617-S618.

Walsh D.C., Stenhouse J.I.T., Clogging of an electrically active fibrous filter material: experimental results and twodimensional simulations, Powder Technology, 93 (1997a) 63-75.

Walsh D.C., Stenhouse J.I.T., The effect of particle size, charge, and composition on the loading characteristics of an electrically active fibrous filter material, Journal of Aerosol Science, 28 (1997) 307-321. DOI: https://doi.org/10.1016/ S0021-8502(96)00434-X

Wang, H., Kasper, G., Filtration efficiency of nanometer-size aerosol particles, Journal of Aerosol Science, 22 (1991) 31-41.

Wang H., Zhao H., Wang K., He Y., Simulation of filtration process for multi-fiber filter using the Lattice-Boltzmann twophase flow model, Journal of Aerosol Science, 66 (2013) 164-178.

Wang H.-C., Comparison of thermal rebound theory with penetration measurements of nanometer particles through wire screens, Aerosol Science and Technology, 24 (1996) 129134.

Wang J., Chen D.R., Pui D.Y.H., Modeling of filtration efficiency of nanoparticles in standard filter media, in: Maynard A.D., Pui D.Y.H. (Eds.), Nanotechnology and Occupational Health, Springer Netherlands, Dordrecht, 2007, pp. 109-
115, ISBN: 978-1-4020-5859-2.

Wang J., Kim S.C., Pui D.Y.H., Investigation of the figure of merit for filters with a single nanofiber layer on a substrate, Journal of Aerosol Science, 39 (2008a) 323-334.

Wang J., Kim S.C., Pui D.Y.H., Figure of merit of composite filters with micrometer and nanometer fibers, Aerosol Science and Technology, 42 (2008b) 722-728.

Wang K., Zhao H., The influence of fiber geometry and orientation angle on filtration performance, Aerosol Science and Technology, 49 (2015) 75-85. DOI: 10.1080/02786826.2014. 1003278

Wang Q., Lin X., Chen D.-R., Effect of dust loading rate on the loading characteristics of high efficiency filter media, Powder Technology, 287 (2016) 20-28.

Wang W., Xie M., Wang L., An exact solution of interception efficiency over an elliptical fiber collector, Aerosol Science and Technology, 46 (2012) 843-851. DOI: 10.1080/ 02786826.2012.671559

Wong J.B., Ranz W.E., Johnstone H.F., Collection efficiency of aerosol particles and resistance to flow through fiber mats, Journal of Applied Physics, 27 (1956) 161-169. DOI: $10.1063 / 1.1722328$

Wongsri M., Tanthapanichakoon W., Kanaoka C., Emi H., Convective diffusional collection of polydisperse aerosols on a dust loaded fiber, Advanced Powder Technology, 2 (1991) 11-23. DOI: https:/doi.org/10.1016/S0921-8831(08)60717-7

Xiao H., Song Y., Chen G., Correlation between charge decay and solvent effect for melt-blown polypropylene electret filter fabrics., Journal of Electrostatics, 72 (2014) 311-314.

Yamada M., Kuramitsu K., Makino K., On estimation of the mechanical strength of the dust layer collected on bag filter cloths, Kagaku Kogaku Ronbunshu, 13 (1987) 13-19.

Yamada S., Seto T., Otani Y., Influence of filter inhomogeneity on sir filtration of nanoparticles, Aerosol and Air Quality Research, 11 (2011) 155-160.

Yang S., Lee G.W.M., Luo C.-H., Wu C.-C., Yu K.-P., Loading characteristics of filter pretreated with anionic surfactant for monodisperse solid particles, Powder Technology, 156 (2005) 52-60.

Yang S., Lee G.W.M., Filtration characteristics of a fibrous filter pretreated with anionic surfactants for monodisperse solid aerosols, Journal of Aerosol Science, 36 (2005) 419-437.

Yang S., Lee W.-M.G., Huang H.-L., Huang Y.-C., Luo C.-H., Wu C.-C., Yu K.-P., Aerosol penetration properties of an electret filter with submicron aerosols with various operating factors, Journal of Environmental Science and Health, Part A, 42 (2007) 51-57. DOI: 10.1080/10934520601015651

Yao Y., Hata M., Wada M., Kanaoka C., Comparison of filter cleaning performance between VDI and JIS testing rigs for cleanable fabric filter, Powder Technology, 180 (2008) 109114.

Yoon K., Kim K., Wang X., Fang D., Hsiao B.S., Chu B., High flux ultrafiltration membranes based on electrospun nanofibrous PAN scaffolds and chitosan coating, Polymer, 47 (2006) 2434-2441. DOI: 10.1016/j.polymer.2006.01.042

Yeh H.-C., Liu B.Y.H., Aerosol filtration by fibrous filters-I. theoretical, Journal of Aerosol Science, 5 (1974a) 191-204.

Yeh H.-C., Liu B.Y.H., Aerosol filtration by fibrous filters-II. 
N217.

Yoneda T., Present status of fabric filter technology, Earozoru Kenkyu, 4 (1989) 278-286. DOI: 10.11203/jar.4.278

Yoneda T., Dust collection technologies by fabric filters, Journal of the Society of Powder Technology, Japan, 38 (2001) 436-445. DOI: $10.4164 /$ sptj.38.436

Yoshioka N., Emi H., Fukushima M., Filtration of aerosols by fibrous filters-Target efficiency at low Reynolds number, Chemical Engineering, 31 (1967a) 157-163. DOI: 10.1252/ kakoronbunshu1953.31.157

Yoshioka N., Emi H., Development in air filtration theory, Chemical Engineering, 31 (1967b) 632-636. DOI: 10.1252/ kakoronbunshu1953.31.632

Yoshioka N., Emi H., Sone H., Experimental examination of impaction efficiency of aerosol particles by means of the single cylinder, Chemical Engineering, 31 (1967c) 10111015. DOI: 10.1252/kakoronbunshu1953.31.1011

Yoshioka N., Emi H., Hattori M., Tamori I., Effect of electrostatic force on the filtration efficiency of aerosol, Chemical Engineering, 32 (1968) 815-820. DOI: 10.1252/ kakoronbunshu1953.32.815

Yoshioka N., Emi H., Matsumura H., Yasunami M., Filtration of aerosols through the fibrous packed bed-On the collection efficiency over the whole range of Reynolds number-,
Chemical Engineering, 33 (1969a) 381-386. DOI: 10.1252/ kakoronbunshu1953.33.381

Yoshioka, N., Emi H., Yasunami M., Sato H., Filtration of aerosols through fibrous packed bed with dust loading, Chemical Engineering, 33 (1969b) 1013-1019. DOI:10.1252/ kakoronbunshu1953.33.1013

Yoshioka N., Emi H., Kanaoka C, Yasunami M., Collection efficiency of aerosol by an isolated cylinder-Gravity and interception predominant region, Chemical Engineering, 36 (1972) 313-319. DOI:10.1252/kakoronbunshu1953.36.313

Yun K.M., Hogan C.J., Matsubayashi Y., Kawabe M., Iskandar F., Okuyama K., Nanoparticle filtration by electrospun polymer fibers, Chemical Engineering Science, 62 (2007) 4751-4759. DOI: https://doi.org/10.1016/j.ces.2007.06.007

Zebel G., Deposition of aerosol flowing past a cylindrical fiber in a uniform electric field, Journal of Colloid Science, 20 (1965) 522-543. DOI: https://doi.org/10.1016/0095-8522(65) 90033-4

Zhao Z.-M., Tardos G.I., Pfeffer R., Separation of airborne dust in electrostatically enhanced fibrous filters, Chemical Engineering Communications, 108 (1991) 307-332. DOI: 10. 1080/00986449108910964

Zhu C., Lin C.-H., Cheung C.S., Inertial impaction-dominated fibrous filtration with rectangular or cylindrical fibers, Powder Technology, 112 (2000) 149-162.

\section{Author's Short Biography}

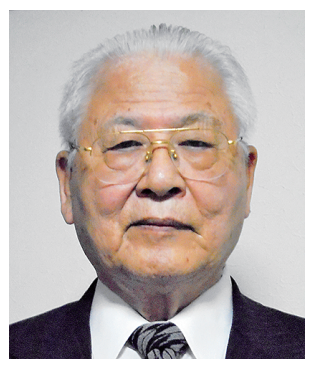

\section{Chikao Kanaoka}

He earned Bachler, Master and Doctor degrees at Chemical Engineering, Kyoto University, 1966, 1968 and 1973, respectively.

He worked as research associate, lecturer (full time), Associate Professor and full Professor at Kanazawa University from 1971 to 2004. From 2004 to 2011, he worked at Ishikawa National College of Technology as a President.

He is now Professor Emeritus, Kanazawa University and Ishikawa National College of Technology.

His research interest is air filtration and bag filtration. 